NBER WORKING PAPER SERIES

\title{
THE ECONOMICS OF 'ACTING WHITE'
}

David Austen-Smith

Roland G. Fryer, Jr.

Working Paper 9904

http://www.nber.org/papers/w9904

\author{
NATIONAL BUREAU OF ECONOMIC RESEARCH \\ 1050 Massachusetts Avenue \\ Cambridge, MA 02138 \\ August 2003
}

This paper is the melding of two independent projects: "Peer Pressure and Job Market Signaling" (AustenSmith) and "The Economics of Acting White" (Fryer). The formal results of these independent papers were essentially identical, thus, we decided to put them together. We are grateful to Roger Myerson for putting us in touch with one another. We are also grateful to Gary Becker, Lawrence Katz, Steven Levitt, Glenn Loury, and seminar participants too numerous to mention for comments and suggestions. Financial support from the John D. and Catherine T. MacArthur Foundation through the Social Interactions and Inequality Network (Austen-Smith) and the National Science Foundation (Fryer: SES-0109196) is gratefully acknowledged. The views expressed herein are those of the authors and not necessarily those of the National Bureau of Economic Research.

(C)2003 by David Austen-Smith and Roland G. Fryer, Jr. All rights reserved. Short sections of text, not to exceed two paragraphs, may be quoted without explicit permission provided that full credit, including (C) notice, is given to the source. 
The Economics of 'Acting White'

David Austen-Smith and Roland G. Fryer, Jr.

NBER Working Paper No. 9904

August 2003

JEL No. D8, J0, I2

\title{
$\underline{\text { ABSTRACT }}$
}

This paper formalizes a sociological phenomenon entitled 'acting white'. The key idea is that individuals face a tension between signaling their type to the outside labor market and signaling their type to a peer group: signals that induce high wages can be signals that induce peer rejection. We prove three basic results: (1) there exists no equilibria in which all types of individuals adopt distinct educational investment levels; (2) when individuals are not too patient, all equilibria satisfying a standard refinement involve a binary partition of the type space in which all types accepted by the group pool on a common low education level and all types rejected by the group separate at distinctly higher levels of education with correspondingly higher wages; and (3) when individuals are very patient, there is an increase in the variation of education levels within the group and an increase in the variance of types deemed acceptable by the group. The more those involved discount the future, the more salient peer pressure becomes and the more homogenous groups become.

\author{
David Austen-Smith \\ Department of Political Science \\ Northwestern University \\ 601 University Place \\ Evanston, IL 60208 \\ dasm@northwestern.edu
}

Roland G. Fryer, Jr.

Harvard Society of Fellows and NBER

1050 Massachusetts Avenue

Cambridge, MA 02138

rfryer@fas.harvard.edu 
Of all the obstacles to success that inner city youth face, the most surprising-and discouragingmay be those erected by their own peers... Many teenagers have come to equate black identity with alienation and indifference. "I use to go home and cry," says Tachelle Ross, 18, a senior at Oberlin High School in Ohio. "They called me white. I don't know why. 'I'd say, I am as black as you are." Promising black students are ridiculed for speaking standard English, showing an interest in ballet or theater, having white friends, or joining activities other than sports...

Honor students may be rebuked for even showing up for class on time. The pattern of abuse is a distinctive variation on the nerd bashing that almost all bright, ambitious students-no matter the color-face at some point in their lives. The anti-achievement ethic championed by some black youngsters declares formal education useless; those who disagree and study hard face isolation, scorn and violence. While educators have recognized the existence of an anti-achievement culture for at least a decade, it has only recently emerged as a dominant theme among the troubles facing urban schools...

Social success depends partly on academic failure; safety and acceptance lie in rejecting the traditional paths to self-improvement.

_ "The Hidden Hurdle," Time, March 16, 1992

\section{Introduction}

Like the Mississippi river divides the United States, so too does the question of race and racial inequality. As W.E.B. Du Bois so eloquently stated, "the problem of the twentieth century is the problem of the colorline." Following in the path laid out by Du Bois, many scholars in many fields have brought their intellectual energies to bear on the causes of racial disparities.

One element of this divide manifests itself in academic achievement (as measured by standardized test scores, GPA, and the like) between minorities and non-minorities. It has been well documented in the empirical social science literatures that after controlling for a potpourri of common explanatory variables, there still remains a substantial achievement gap between blacks and whites (Jencks and Phillips, 1998). Gaining a better understanding of the underlying causes of the gap is a question of great importance ${ }^{1}$. Current explanations range from the genetic inferiority of minorities (Herrnstein and Murray, 1994 and Jensen, 1998) to differences in neighborhoods and environment (Brooks-Gunn and Duncan, 1997). Proponents of the genetics argument contend that blacks are predisposed, a priori, to poor performance as compared to their white counterparts, due solely to innate biological differences between the races ${ }^{2}$. This argument, however, runs in

\footnotetext{
${ }^{1}$ To this effect, Christopher Jencks and Meredith Phillips write "Reducing the black-white test score gap would do more to promote racial equality than any other strategy that commands broad political support."

${ }^{2}$ Rushton (2000) has a similar view. He proposes that there exists genetic comparative advantages betwen different races. For example, Kenyans are predisposed to be better runners and Russians better mathematicians.
} 
direct conflict with the substantial amount of biological evidence that fails to pin any difference in the biological construct of human beings to race (Olson, 2002). Further, new evidence reported in Fryer and Levitt (2002) finds that the black-white achievement gap is essentially zero when kids enter school, after controlling for a parsimonious set of controls. On the other hand, the environmental proponents suppose that blacks are simply in different environments, as compared to whites, (financially, socially, etc.) and the residual gap is due to the substantial difference in unobservable environmental or neighborhood effects (with regards to limitations of the data). This argument, however, does not account for the empirical observation that blacks still do substantially worse than whites in middle class suburban neighborhoods, where presumably the social and financial constructs are very similar (Ferguson, 2001). Thus, we are left with an important paradox. First, if genetics is the answer, then where are the biological differences that are tied to race? Second, if it is purely the environment, then why are blacks and whites in the same "privileged" environments performing differently? The appropriate public policy choice to address the achievement gap depends critically on the underlying explanation.

This paper seeks to resolve the paradox by formalizing a phenomenon entitled 'acting white'. 'Acting white' is a situation that is believed to manifest itself in the United States within black and Hispanic neighborhoods. It suggests that adolescents within these neighborhoods can have tremendous disincentives to invest in particular behaviors (i.e. education, ballet, etc.) due to the fact that they may be deemed as a person who is trying to act like a white person (a.k.a. "selling-out") ${ }^{3}$. Such a label, in some neighborhoods, can carry penalties that range from being deemed a social outcast, to being beaten or killed ${ }^{4}$. In essence, the need or desire to be accepted by one's peers leads individuals to behave in ways they would otherwise avoid. Similar arguments motivate recent work by Akerlof (1997) and Akerlof and Kranton (1999) on the economic implications of social conformism and cultural "identity". Inter alia, these authors survey a litany of works, both academic and autobiographical, testifying to the tension many individuals of a minority culture feel between doing what is expected to remain accepted by their peers or social group (be it predicated on race, ethnicity or gender), and doing what is expected to succeed in a world dominated by those in the majority culture.

While the 'acting white' hypothesis may explain sub par academic performance in low-income black neighborhoods, one potential puzzle is the black middle-class. It is well documented that blacks in middle class neighborhoods are not achieving, academically, at the same rate as their white counter parts (PattilloMcCoy, 1999). This has puzzled many environmental proponents, since presumably, blacks and whites in these neighborhoods have similar environmental conditions. To understand this, one has to consider the impact of racial segregation in housing. Due to a peculiar history, the black middle class are much more

\footnotetext{
${ }^{3}$ In affluent neighborhoods, blacks and Hispanics can endure the same litmus test; once confronted by another individual within their same race who wants to know why they are acting in a certain way. More specifically, blacks in suburban schools may face the same dis-incentives, just less often (see Pertroni and Hirsch, 1970 and Patillo-McCoy, 1999).

${ }^{4}$ This is not an exaggeration. In Greenville, South Carolina, two adolescants were convicted of "second degree lynching" after attempting to hang a peer they accused of 'acting white.' There is no cite for this, as it was handled in juvenile court and the records are sealed. Sam Stillwell represented the defendant.
} 
likely to live in neighborhoods that border poor black neighborhoods ${ }^{5}$. Jargowsky and Bane (1991) show that black middle class neighborhoods are much more likely to create a buffer zone between the black poor and white non poor. Massey and Denton (1993) report that blacks with college educations have more than a 20 percent chance of coming in contact in their neighborhood with someone receiving welfare, whereas college-educated whites have an 8 percent chance. This pattern was repeated for interaction with blue-collar workers, high school drop-outs, and the unemployed.

The central underlying idea of 'acting white,' is that individuals face a tension between signaling their type to the outside labor market and signaling their type to a peer group: signals that induce high wages can be signals that induce peer rejection. It is important to emphasize at the outset that, in the model, firms are assumed to have no interest in any employee's group membership, and groups are assumed not to have any basic preference over whether a potential member is employed or wealthy ${ }^{6}$. Consequently, there is no intrinsic conflict built into the model between individuals being highly educated and employed, and being members of a group. At the same time, other things equal, all types strictly prefer to be accepted rather than rejected by their peer group; the group, however, is concerned only to accept those individuals who will be reliable group members in that they can be depended upon to support the group in difficult times. Examples of this sort of reliability are not hard to find; they range from gang members who can be trusted not to betray other members when subjected to police investigation, to residents of a community who can be relied upon to invest the time and effort to help their neighbors when they are in need (see Anderson, 1999, for more detailed examples). An important characteristic of these and many other examples, one that in large part defines what it is to be a member of social group rather than a strictly economic market, is that the costs of membership are in terms of personal time and effort, not money per se.

Although the assumption that all individuals prefer to be accepted by their peers is taken as primitive (and predicated on the sociological and psychological evidence that such preferences exist and are widespread (Asch, 1952)), the operationalization of which types constitute reliable group members is endogenous to the model. This turns out to be far from a single type, and gives rise naturally to a notion of peer pressure. The principal result is an existence and characterization of a specific class of equilibria, central to the canonic job signaling literature initiated by Spence (1974). Unlike in the canonic model where this class consists exclusively of equilibria in which all types invest in distinct levels of education (i.e. separate) and so attract distinct wages, in the present model there exist no separating equilibria. Instead, equilibria in the class comprise a set of types all of whom choose the same low education level (i.e. pool) while the remaining types separate, with the lowest separating type making a significantly higher investment in education and earning a correspondingly higher wage than those adopting the pooling investment. The resulting binary partition of types corresponds to those accepted by their peers (the pooling types) and those rejected (the separating types). And it is worth emphasizing that nothing is built into the model that requires accepted types to adopt a common educational investment; it is an equilibrium outcome. On the other hand, the specific class

\footnotetext{
${ }^{5}$ See Pattillo-McCoy (1999), chapter 2, for a nice discussion on the evolution of the black middle class.

${ }^{6}$ This is an important point of departure from the standard explanations in the sociology and anthropolgy literatures.
} 
of equilibria is empty when individuals value the future sufficiently highly. In this case, a natural extension of the original class of equilibria leads to some variation in the education investment choices among those accepted by the peer group and a simultaneous increase in the variance of types deemed acceptable. Inter alia, therefore, the model supports some comparative statics on group composition and intra-group behavior as functions of individuals' discount factors.

Although our model is the first attempt at incorporating 'acting white' into a formal rational choice framework $^{7}$, one can discern a hint of the 'acting white' problem in some of the early writings of Franklin E. Frazier (1957). More recently, anthropologists Signithia Fordham and John Ogbu (1986) attempt to explain the 'acting white' phenomenon by, what we will refer to as, the oppositional culture hypothesis. Fordham and Ogbu (1986) posit that the oppositional culture frame of reference is applied by minorities in selective situations. From their perspective, the target areas appear to be those traditionally defined as prerogatives of white Americans, both by white people themselves and by minorities. This hypothesis states that the observed disparity between blacks and whites stems from the following factors: (1) white people provide them with inferior schooling and treat them differently in school; (2) by imposing a job ceiling, white people fail to reward them adequately for their academic achievement in adult life; and (3) black Americans develop coping devices which, in turn, further limit their striving for academic success. In other words, a major reason that black students do not do well in school is that they experience inordinate ambivalence and affective dissonance in regard to academic effort and success. Fordham and Ogbu propose that this problem arose partly because white Americans traditionally refused to acknowledge that black Americans were capable of intellectual achievement, and partly because black Americans subsequently began to doubt their own intellectual ability, began to define academic success as white people's prerogative, and began to discourage their peers, perhaps unconsciously, from emulating white people in academic striving (i.e. 'acting white'). ${ }^{8}$

There have been several studies that fail to find empirical justification for an oppositional culture (Cook and Ludwig 1998; Ainworth-Darnell and Downey 1998; and Ferguson 2001). Cook and Ludwig's work ask

\footnotetext{
${ }^{7}$ Fryer (2003) develops a more general model of the tension between investments in (local) cultural and (global) human capital, of which 'acting white' can be a consequence.

${ }^{8}$ Generally, there are large literatures concerning group influences on individual decision-making in sociology and social psychology, yet efforts to develop more formal models addressing how such influences affect economic decisions in general, let alone with regard to education and investment in human capital, are relatively new. And within the formal literature, most of the work is devoted to understanding the economic implications of (more or less) given social norms. Akerlof (1976, 1980) are early examples on how given norms of conformity and fairness influence labour market behaviour and collective action. Recent contributions beyond those cited earlier include Bernheim (1994), who provides an elegant signaling model in which both conformism and 'deviant' behaviours arise endogenously in equilibrium; Lindbeck and Weibull (1999) look at a political economy model of redistributive taxation and labour supply in which the tax-rate and the intensity to which 'living off one's work' is a significant social norm are endogenous; Cole et al (1992) and contributions to a special issue of the Journal of Public Economics (1998) devoted to norms and status explore various models of social interaction and economic behaviour (see also Kandori, 1992). While much of this literature bears in some way on the issue here, none of it directly considers the role of peer pressure on human capital formation.
} 
three critical questions: (1) Do African-American adolescents report greater alienation from school than non-Hispanic whites? (2) Does academic success lead to social ostracism among black adolescents? (3) Do the social costs or benefits of academic success differ by race? For each question, their answer based on analysis of nationally representative data is, "apparently not." Further, sociologists Ainworth-Darnell and Downey analyzed the same national data and came to essentially similar conclusions. However, their findings support the additional hypothesis that blacks have more problems than whites in a category they call "skills, habits and styles." They find that variables in this category, as distinct from oppositional attitudes about achievement, help in a small way to explain the achievement gap in the data that they analyzed. One important contribution in this literature is Ferguson (2001). In a beautifully detailed investigation of the academic achievement disparities within an integrated school in Shaker Heights, Ohio, he also suggests that the oppositional culture hypothesis is misplaced, though his argument is more subtle. He believes that the opposition, if any, is not directed towards whites specifically as individuals; however, the opposition is directed toward white supremacy as an ideal-in which stigmas are kept alive and from which insinuations of black inferiority can persist. Black collective identity then serves as a mechanism of mutual validation and shields off the rumors of genetic inferiority.

Despite the evidence against the oppositional culture hypothesis, there are some objections, two of which are particularly germane here. First, the works by Cook and Ludwig (1998), Ainworth-Darnell and Downey (1998), and Ferguson (2001), are not direct tests of the oppositional culture hypothesis. Fordham and Ogbu (1986) analyze an inner city near Washington D.C. Capital High, the fictitious name given to the high school where the ethnographic data was collected, is a predominantly black high school (99\%) in a black low income neighborhood. The others, however, use either nationally representative samples or data from one integrated high school in Ohio. In other words, if anything, the samples claiming to rebuke the oppositional culture hypothesis can do so only in so far as they cast doubt on the external validity of Fordham and Ogbu's field work. Whether the minority students in Capital high (where the ethnographic data was collected) or any other high school limit their academic pursuits because of the fear of 'acting white', we don't know'. Second, there is a tremendous amount of anecdotal evidence that the fear of 'acting white' is a serious debilitator for minority youth. Indeed, a search of major newspapers yields over seventy articles since 1985 on the effects of 'acting white.' In June of 1999, the ABC 20/20 News Hour aired a segment on the topic of 'acting white' as it applies among black high school students. The setting was a racially mixed high school in Wisconsin where reporter Charles Gibson interviewed students who had been accused of 'acting white' and others who had made the accusations. When Gibson suggested to a young man that trying to hold others back from reaching their full potential was not a good thing to do, one student's response was, "Yeah, but they were kickin' their old friends to the side for new friends, and that's not right either." A young woman in a similar exchange retorted, "Yeah, I'm gonna call you actin' white if you act like you think you're better than me."

\footnotetext{
${ }^{9}$ In another example, Suskind (1998) reports of the trials and tribulations of Cedric Jennings, a student in one of the most blighted high schools in inner-city Washington, D.C. The book begins with Cedric hiding in the chemistry lab, trying to escape the "cat calls" of "nerd" and "whitey" he will endure at the schools award assembly-which honors academic achievement.
} 
Another young man, now a record producer and rap recording artist, had gone away to Exeter, the elite private preparatory school, and come back dressing and speaking differently from when he left. He was accused of acting white. His interpretation of why former friends in the community were a little "put off" or "taken aback," was not that they resented his success. Instead, his interpretation was sensitive to their concern that he might be trying to escape the stigma. He said they wondered if he had "sold out" to the Other part of society that looked down on people like themselves. He responded by finding ways to share his success and, "By letting them know that I'm not ashamed. I can still speak slang. I can still rap, even."

The above rhetoric seems intuitive. It does not need the oppositional culture assumption to validate the behavior. Yet, it clearly suggests, as we assume in the formal model, that blacks do not really care about one's perceived success, as long as it does not conflict with their "loyalty" towards the black community. This is an extremely important, subtle, point that is also evident in the Fordham (1991) ethnography.

\section{Model}

There are an infinite number of discrete time periods, indexed $t=0,1,2, \ldots$. The initial period, $t=0$, is distinguished as the "school years"; periods $t>0$ are collectively referred to as the "post-school years". In principle, three sorts of agent interact in each period: individuals, firms and a (suitably anthropomorphized) peer group. We begin with a detailed description of the basic building blocks of our model.

\section{A. The Basic Building Blocks}

Individuals An individual's abilities (types) are private information to the individual and chosen by Nature at the start of the school years according to a smooth common knowledge c.d.f. $F$ with density having support $[0, \bar{\theta}), \bar{\theta}$ finite. Types, once chosen, are fixed over time. With some abuse of terminology, where there is no ambiguity, we shall refer to an individual of type $\theta$ simply as "individual $\theta$ ". In addition to a type, an individual is endowed with one unit of effort in each period. In each period $t$, the individual chooses how to allocate his or her endowment of effort; any effort level expended on any activity in a period is commonly observable and effort is nonstorable. ${ }^{10}$

In the initial period $t=0$, the "school years", individual $\theta$ allocates effort between leisure and a once-andfor-all investment in education. Since education and effort expended on acquiring education are identified without loss of generality here, let $s \in[0,1]$ denote the level of education acquired, or input of individual effort to education expended, in the school years. Although the output of education for any level of effort is independent of an individual's type, the cost of effort so expended is not. In addition to the direct opportunity cost of effort used for education in the school years, assume there is a further cost of any

\footnotetext{
${ }^{10}$ It is perhaps more natural to think of an individual allocating time, rather than observable effort. The use of the effort terminology, however, is to avoid the possibility of any notational confusion between time periods and an individual's allocation of time within any period.
} 
educational investment to individual $\theta, c(s, \theta) \geq 0$. As in the canonical signaling literature, the cost function $c$ is assumed to satisfy

$$
c_{s}>0, c_{\theta}<0 ; c_{s s}>0, c_{s \theta}<0 \forall s>0 ; \lim _{s \rightarrow 0} c_{s}(s, \cdot)=0 \text { and } \lim _{s \rightarrow 1} c_{s}(s, \cdot)=\infty,
$$

where subscripts denote partial derivatives in the usual way. Thus effort is costly for all types but higher types find it less costly to acquire any given level of education. At the end of the school years, an individual's education level is fixed and competitive bidding between firms leads to post-school employment at an endogenously determined per period wage, $w \geq 0$.

At the start of any period $t \geq 1$, individual $\theta$ may or may not be an accepted member of her peer group. If $\theta$ is not such an accepted member then she consumes one unit of leisure and her given wage; on the other hand, if is $\theta$ an accepted member of the group then $\theta$ may face a period $t$ effort allocation problem. ${ }^{11}$

Let individual $\theta$ be an accepted member of the peer group for period $t \geq 1$. Membership is valued because, other things equal, leisure time spent in the group is valued more highly than leisure time spent outside the group. Group membership, however, involves some costs on occasion. Specifically, while no direct contribution is required of any individual accepted by the group in the school years, at the start of each subsequent period $t=1,2, \ldots, \theta$ may or may not be required to make a contribution to the group's well-being. We assume that such contributions are observable and that their costs to an individual are measured in terms of effort. Suppose that in any period $t>0$, Nature chooses a required contribution $\kappa_{t} \in\{0, k\}$ from the individual to the group, $0<k<1$; for future reference, let $\pi \in(0,1)$ be the (date invariant) probability that $\kappa_{t}=0 .{ }^{12}$ The cost to an individual $\theta$ of making a contribution $k$ is assumed to depend on the individual's type. The cost to $\theta$ of making a contribution $k$, measured in terms of effort, is $\theta k$, so higher types find it more onerous to comply than lower types and any type $\theta>1 / k$ is unable to fulfill a demand to contribute $k$ (throughout, assume $\bar{\theta}>1 / k$ ). The effort allocation problem in period $t$ for an individual member of the peer group, therefore, is on whether or not to contribute to the group if called upon do so in that period.

For any $t \geq 0$, let $a_{t} \in\{0,1\}$ denote whether the individual is rejected $\left(a_{t}=0\right)$ or accepted $\left(a_{t}=1\right)$ by his or her peer group in $t$, and let $v\left(l_{t} \mid a_{t}\right)$ be the individual's period $t$ payoff from leisure $l_{t} \in[0,1]$. Then given the individual's type $\theta$ and school year education decision, $s \in[0,1], \theta$ 's period $t=0$ payoff is,

$$
v\left(1-s \mid a_{0}\right)-c(s, \theta)
$$

Assume $v(l \mid \cdot)$ twice differentiable concave increasing in $l$ on $(0,1)$. Further assume that having no leisure at all is worthless irrespective of group acceptance, and that both total and marginal values from consuming

\footnotetext{
${ }^{11}$ Adding a discrete effort cost for showing up to work in any period and assuming firms fire an employee who ever fails to show up, leaves the following analysis unaffected. However, it turns out that in equilibrium no individual earning a strictly positive wage ever fails to show up for work.

${ }^{12}$ As suggested in the Introduction, an interpretation of such contributions here is in terms of helping out in difficult times, where these fall upon the group or the average group member with frequency $1-\pi$. And while costs might then be more naturally modeled as continuous variables, doing so adds little further insight.
} 
any strictly positive amount leisure are greater as an accepted group member than otherwise: formally, $v(0 \mid 1)=v(0 \mid 0)=0$ and, for all $l>0$,

$$
v(l \mid 1)>v(l \mid 0) \text { and } v^{\prime}(l \mid 1)>v^{\prime}(l \mid 0) .
$$

In the case that $\theta$ is an accepted group member in some $t>0$ and is asked to make a contribution $\kappa_{t}$, let $d_{t} \in\{0,1\}$ denote $\theta$ 's decision on whether or not to comply (respectively, $d_{t}=1$ or $=0$ ). Then in any post-school year period, $\theta$ 's period $t>0$ payoff from choosing $d_{t}$ is,

$$
w+v\left(1-a_{t} d_{t} \theta \kappa_{t} \mid a_{t}\right)
$$

Firms Assume there are at least two identical and noncollusive firms which, at the end of the initial period $t=0$, engage in Bertrand bidding for employees to produce a homogenous and nonstorable product in each period $t=1,2, \ldots$. The salient features of an employee for a firm are education and type. So an employee is characterized by a pair $(s, \theta)$ and the net value to a firm hiring employee $(s, \theta)$ at a wage-rate $w \geq 0$ in any period $t>0$ is

$$
Y_{t}(w, s, \theta)=[y(s, \theta)-w] .
$$

Assume (for convenience) that firms do not discount the future and that

$$
y_{s}>0, y_{\theta}>0 ; y_{s s} \leq 0, y_{s \theta}>0 \text { and } y(0, \cdot) \equiv 0 .
$$

Firms have no interest in any individual save in his or her capacity as an employee, defined by a pair $(s, \theta)$. In particular, the firm neither observes nor cares about what any individual does while away from work. Nevertheless, it is evidently possible to imagine a variety of employment contracts in this setting. Among other things, under the assumption that per period output is observable, the firm learns any employee's type for sure by the end of the first employment period. So in general we might expect to observe wage contracts depending in part on future realized output. But dealing explicitly with such complications here distracts greatly from the focus of the paper. ${ }^{13}$ Consequently we shall assume them away by presuming firms sufficiently large, first, that average realized output from individuals with a given education level accurately reflects the firms' expectations at the time of recruitment and, second, to render individual contract renegotiation unprofitably expensive. So feasible employment contracts are taken to specify a constant wage-rate over time.

Peer Group To avoid trivialities, assume throughout that the peer group is nonempty. Although, other things equal, individuals prefer inclusion in the peer group they may not in fact be accepted by the (suitably anthropomorphized) group. Just as group acceptance is important to individuals, individuals yield value to the group as a whole through consumption externalities, contributions, collegiality and so forth. We will, essentially, black-box the interesting issue of endogenous peer group formation. In a related paper,

\footnotetext{
${ }^{13}$ If individuals' types are fully revealed during the school years, then there is clearly no room for subsequent contract renegotiation. But this is not true when equilibrium involves any pooling.
} 
Fryer (2003) deals explicitly with this, whereas we take the peer group as given and analyze the implications in a richer economic environment.

Assume that if an individual is rejected by the group during that individual's school years, $t=0$, then the individual cannot be accepted in any period $t$ thereafter (it turns out that this is without any loss of generality in the current model); however, an individual accepted by the group at $t=0$ may be rejected in any subsequent period. Normalize group payoffs in any period $t=1,2, \ldots$ to be zero in the case that a given individual is rejected at $t=0$. Suppose the individual is accepted at $t=0$ and remains accepted at the end of period $t-1>0$. At the beginning of the period $t$, the group decides whether to accept $\left(a_{t}=1\right)$ or reject $\left(a_{t}=0\right) \theta$ for that period, following which Nature randomly chooses the group contribution $\kappa_{t} \in\{0, k\}$ required of $\theta$ and the individual either does $\left(d_{t}=1\right)$ or does not $\left(d_{t}=0\right)$ make the contribution; both the realization $\kappa_{t}$ and the individual's decision are observed by the group.

Let $g\left(a_{t}, d_{t}, \kappa_{t}\right)$ be the period $t>0$ payoff to the group from action $a_{t}$, given the individual makes decision $d_{t}$ when the required contribution is $\kappa_{t}$. Then, for all realizations $\kappa_{t}, g\left(0, d_{t}, \kappa_{t}\right)=0$ for all $d_{t}$ and

$$
g\left(1,1, \kappa_{t}\right)=b>0 \geq g\left(1,0, \kappa_{t}\right)=-B \kappa_{t} .
$$

The benefits $B, b$ are (for simplicity) taken to be independent of $t$ and $\kappa_{t}$.

Thus, irrespective of whether the individual chooses to contribute, the group receives a zero payoff when it rejects the individual, but the group's payoff when it accepts the individual is contingent on the individual's behavior. The key feature of the group's payoffs for what follows is that the group is strictly worse off having accepted an individual who chooses not to make her required contribution than it would be were such an individual rejected; i.e. $-B k<0$. When $\kappa_{t}=0$, the group strictly prefers to have accepted the individual for period $t .^{14}$

The group's payoffs above are conditional on $t>0$. The group's initial decision on whether to accept an individual, however, is taken during the school years $t=0$. Assume that the net period $t=0$ benefits to the group of accepting an individual are normalized to zero (for example, there might be some cost to the group for initiating a new member, offsetting any $t=0$ expected benefit of adding the individual).

Recall that $1-\pi$ is the probability that the individual is required to contribute $k>0$ to the group in any period $t>0$ in which $a_{t}=1$. The following assumption is maintained throughout.

$$
\pi<\min \left\{\frac{B k}{B k+b}, \frac{v(1 \mid 0)}{v(1 \mid 1)}\right\} .
$$

Assuming $\pi$ is strictly smaller than $B k /[B k+b]$ is a non-triviality condition; as will become clear shortly, without the assumption all individuals are always accepted into the group. Substantively, assuming $\pi$ is smaller than $v(1 \mid 0) / v(1 \mid 1)$ is equivalent to assuming that individuals prefer surely consuming their leisure time on their own, to the expected value of being an accepted group member when there is a chance that

\footnotetext{
${ }^{14}$ These payoffs are a reduced form of a more general model of repeated interaction in which agents use "grim-trigger" strategies. See Fryer $(2001,2003)$. Modeling the payoffs in this way further distinguishes our analysis from other signaling models such as Bernheim (1994).
} 
remaining in the group requires having no leisure at all to consume; that is $\pi v(1 \mid 1)+(1-\pi) v(0 \mid 1)<v(1 \mid 0)$. Technically, the assumption precludes having to deal explicitly with some boundary cases in the later analysis.

Finally, just as firms are presumed to observe only aggregate output from those of a given education level, assume that if a group member is an employee in some firm (i.e. $w>0$ ), then the group cannot identify the specific output of the firm attributable to that member. This seems quite innocuous.

\section{B. Strategies}

The basic solution concept used here is Perfect Bayesian equilibrium.

At $t=0$, the school years, an individual learns his or her type $\theta \in[0, \bar{\theta})$ and chooses an observable effort level $s \in[0,1]$ according to an education investment strategy,

$$
\sigma:[0, \bar{\theta}) \rightarrow[0,1]
$$

Having observed the individual's choice of effort $\sigma(\theta) \in[0,1]$, the peer group chooses whether or not to accept the individual into the group. The group's initial acceptance strategy is a choice,

$$
\alpha_{0}:[0,1] \rightarrow[0,1]
$$

where, for any $s \in[0,1], \alpha_{0}(s)$ is the probability the group accepts the individual in the school years. While rejection in the school years involves rejection for all subsequent periods (which turns out to be consistent with equilibrium behavior), acceptance is contingent on future decisions.

Firms observe an individual's effort (equivalently, educational achievement), $\sigma(\theta) \in[0,1]$, at the end of the period and engage in Bertrand wage bidding for his or her labour. Given that wages cannot be renegotiated in subsequent periods, a wage strategy is a map,

$$
w:[0,1] \rightarrow[0, \infty)
$$

Given (5), it is routine that the equilibrium wage offered an individual with education level $s$ is simply

$$
w\left(s,\left.F\right|_{s}\right)=\int_{0}^{\bar{\theta}} y(s, \theta) d F(\theta \mid s)
$$

where $\left.F\right|_{s} \equiv F(\theta \mid s)$ describes the firm's (and group's) conditional beliefs regarding the individual's type, and the firm makes zero expected profits at the time of recruitment. Once the wage is set, the firm has no further decision to make. Hereafter, therefore, we take (8) as given.

As will become clear later, there is no loss in generality by restricting attention to pure strategies only during the post-school years. For $t \geq 1$, a group history $h_{t}$ is a description of all the actions taken in periods $t^{\prime}=0,1,2, \ldots, t$ by Nature $\left(\kappa_{t} \in\{0, k\}\right)$, the individual $\left(\sigma(\theta), d_{t} \in\{0,1\}\right)$, and the group $\left(a_{t} \in\{0,1\}\right)$. For $t=0$ and realization $a_{0}$ of the strategy $\alpha_{0}(\sigma(\theta))$, set $h_{0}=\left(\sigma(\theta), w\left(\sigma(\theta),\left.F\right|_{\sigma(\theta)}\right), a_{0}\right)$ and, for all $t \geq 1$, set

$$
h_{t}=\left(h_{t-1},\left(\kappa_{t} ; d_{t} ; a_{t}\right)\right) \text {. }
$$


Let $H_{t}=\left\{h_{t}\right\}$ denote the set of all possible group histories for $t \geq 0$. Then we can define the peer group's period $t \geq 1$ (pure) strategy as a function,

$$
\alpha_{t}: H_{t-1} \rightarrow\{0,1\}
$$

where $\alpha_{t}\left(\kappa_{t}, h_{t-1}\right)$ is the probability the group accepts the individual in period $t$.

Given individuals' preferences are separable in wages, period $t \geq 1$ (pure) strategy for the individual is a function,

$$
\psi_{t}:\{0, k\} \times[0, \bar{\theta}) \times H_{t-1} \rightarrow\{0,1\} .
$$

Putting the pieces together, a strategy for an individual is a list, $\left(\sigma,\left\{\psi_{t}\right\}_{t=1}^{\infty}\right)$; a strategy for the group is a list, $\left(\alpha_{0},\left\{\alpha_{t}\right\}_{t=1}^{\infty}\right)$; and, under the assumptions on contracts, the (symmetric) wage strategy for any firm is fixed to be the function $w$ defined by (8).

\section{Payoffs}

Once an individual's wage rate is determined at the end of the school years, it is fixed thereafter. Hence the discounted expected payoff for an individual of type $\theta$, given strategies $\left(\left(\sigma,\left\{\psi_{t}\right\}_{t=1}^{\infty}\right),\left(\alpha_{0},\left\{\alpha_{t}\right\}_{t=1}^{\infty}\right), w\right)$, is:

$$
\begin{aligned}
& u\left[\left(\sigma,\left\{\psi_{t}\right\}_{t=1}^{\infty}\right),\left(\alpha_{0},\left\{\alpha_{t}\right\}_{t=1}^{\infty}\right), w ; \theta\right]= \\
& v\left(1-\sigma(\theta) \mid \alpha_{0}(\sigma(\theta))\right)-c(\sigma(\theta), \theta)+ \\
& \frac{\delta}{1-\delta} w\left(\sigma(\theta),\left.F\right|_{\sigma(\theta)}\right)+\sum_{t=1}^{\infty} \delta^{t} E v\left(l_{t}\left(\psi_{t}\left(\kappa_{t}, \theta, h_{t-1}\right)\right) \mid \alpha_{t}\left(h_{t-1}\right)\right),
\end{aligned}
$$

where $\delta \in(0,1)$ is the individual's discount factor, $E$ is the expectations operator over Nature's choice of contribution $\kappa_{t}$ and, by an abuse of notation, $v\left(\cdot \mid \alpha_{0}(\sigma(\theta))\right)=\alpha_{0}(\sigma(\theta)) v(\cdot \mid 1)+\left[1-\alpha_{0}(\sigma(\theta))\right] v(\cdot \mid 0)$.

To define payoffs for the group, first suppose the group accepts the individual in the school years, $a_{0}=1$, and, for any $t \geq 1$, recall $g\left(a_{t}, d_{t}, \kappa_{t}\right) \in\left\{b,-B \kappa_{t}, 0\right\}$ is the stage-game payoff from decisions $\left(a_{t}, d_{t}\right)$ when the required contribution is $\kappa_{t}$. Let $\gamma$ denote the peer group's discount factor. Now, define

$$
\begin{aligned}
z\left[\left(\sigma,\left\{\psi_{t}\right\}_{t=1}^{\infty}\right),\left(\alpha_{0},\left\{\alpha_{t}\right\}_{t=1}^{\infty}\right), w\right]= \\
\left\{\begin{array}{l}
0 \text { if } a_{0}=0 \\
\sum_{t=1}^{\infty} \gamma^{t} \int_{0}^{\bar{\theta}}\left[E g\left(\alpha_{t}\left(h_{t-1}\right), \psi_{t}\left(\kappa_{t}, \theta, h_{t-1}\right), \kappa_{t}\right)\right] d F\left(\theta \mid h_{t-1}\right) \text { else }
\end{array}\right.
\end{aligned}
$$

\section{Equilibrium}

Fixing any firm's strategy to be given by (8), an equilibrium is a strategy $\left(\sigma^{*},\left\{\psi_{t}^{*}\right\}_{t=1}^{\infty}\right)$ for an individual and a strategy $\left(\alpha_{0}^{*},\left\{\alpha_{t}^{*}\right\}_{t=1}^{\infty}\right)$ for the group, constituting sequentially rational mutual best responses at every subgame and supported by beliefs over an individual's type, $F(\theta \mid \cdot)$, derived from Bayes rule wherever possible. To find equilibria to the game, we begin with behavior in the post-school years. 


\section{A. The Post-School Years}

There are many equilibria to the model described above, but in what follows we focus only on those in which the group adopts a simple, familiar and intuitive strategy in the subgame beginning $t=1$, viz. Conditional on accepting an individual in the school years $(t=0)$, the group continues to accept that individual so long as he or she has made the required contribution to group maintenance in every preceding period; should the individual ever elect not to contribute as required in some period $t \geq 1$, the group rejects the individual in every period thereafter. Formally, the group's strategy contingent on accepting an individual during the school years, $\alpha_{0}(\sigma(\theta))=1$, is taken to be:

$$
[P 1]: \forall t \geq 1, \alpha_{t}^{*}\left(h_{t-1}\right)=1 \Leftrightarrow\left[h_{t-1}: d_{t-1}=1\right]
$$

Call the group strategy $[P 1]$ the peer pressure strategy.

Contingent on being accepted by the group in the school years, an individual's best response to the peer pressure strategy depends on his or her type. Formally, for any fixed type $\widehat{\theta} \in[0, \bar{\theta})$ define the strategy $\left.\psi_{t}^{*} \widehat{\theta}\right]$ by:

$$
[P 2]:\left\{\begin{array}{c}
\forall \theta \leq \widehat{\theta}, \psi_{t}^{*}[\widehat{\theta}]\left(\kappa_{t}, \theta, h_{t-1}\right)=1 \text { for all } \kappa_{t} \\
\forall \theta>\widehat{\theta},\left[\psi_{t}^{*}[\widehat{\theta}]\left(0, \theta, h_{t-1}\right)=1, \psi_{t}^{*}[\widehat{\theta}]\left(k, \theta, h_{t-1}\right)=0\right]
\end{array}\right\} .
$$

Under the strategy $\psi_{t}^{*}[\widehat{\theta}]$, any type lower than $\widehat{\theta}$ always contributes and any type greater than $\widehat{\theta}$ only contributes when the required cost is low.

We are now in a position to describe the post-school years behavior of interest. The proof of Proposition 1 , as with all subsequent formal results, is confined to an Appendix.

Proposition 1 Let $\sigma(\theta)$ be individual $\theta$ 's school year educational investment and suppose, conditional on being accepted by the group in the school years, the individual's post-school year behavior is described by [P2]. Then $\alpha_{0}(\sigma(\theta))=1$ and [P1] jointly constitute a best response to $\sigma(\theta)$ and [P2] if and only if

$$
F(\hat{\theta} \mid \sigma(\theta)) \geq \frac{[(1-\pi) B k-\pi b](1-\gamma)}{[b+(1-\gamma) B k](1-\pi)} .
$$

Furthermore, there exists a unique type $\widehat{\theta}(\delta)<1 / k$ such that, conditional on being accepted by the group in the school years, the strategy $\psi_{t}^{*}[\widehat{\theta}(\delta)]$ defined by $[P 2]$ is a best response to $[P 1]$. Moreover, $\widehat{\theta}(\delta)$ is strictly increasing in $\delta$ on $[0,1)$; and $\lim _{\delta \downarrow 0} \widehat{\theta}(\delta)=0$.

Assume hereon that the post-school years' behavior is as described by Proposition 1 and call any equilibrium to the full game in which Proposition 1 describes post-school year behavior, a peer pressure equilibrium.

Proposition 1 says that the peer pressure strategy induces a unique threshold strategy $\psi_{t}^{*}[\widehat{\theta}(\delta)]$ as a best response by individuals belonging to the group. The critical type $\widehat{\theta}(\delta)$ is defined by precisely that type who, conditional on being accepted during the school years, is indifferent between contributing and not contributing the high cost when so required (where, given the group uses the peer pressure strategy, not 
contributing the high cost results in being rejected). As usual, the more individuals' care about the future, the less they have to gain from any short run free-riding and so this critical type increases in the discount factor. It follows that, to accept an individual in the school years and support the peer pressure strategy, the belief the group must hold regarding the individual's type, $F(\hat{\theta} \mid \sigma(\theta))$, must be no smaller than the quantity

$$
F_{0} \equiv \frac{[(1-\pi) B k-\pi b](1-\gamma)}{[b+(1-\gamma) B k](1-\pi)}
$$

Assumption (7) insures the critical value $F_{0}$ is strictly positive and it is easy to check that $F_{0}$ is decreasing in $\pi$, the group's discount factor $\gamma$ and the benefit $b$, but increasing in $B k$. Consequently, the critical type $\widehat{\theta}(\delta)$ (at least in part) vindicates the group never taking back a member who is rejected because of failing to contribute as required: in equilibrium, the types rejected for not contributing are precisely those types who would never contribute a high cost and who are thus unacceptable to the group.

Hereafter, to save notation we leave the dependency of the individual's peer pressure equilibrium strategy on the critical type $\widehat{\theta}(\delta)$ implicit and simply write $\left.\psi_{t}^{*}(\cdot) \equiv \psi_{t}^{*} \widehat{\theta}(\delta)\right](\cdot)$.

\section{B. The School Years}

Given any educational effort $\sigma(\theta)$ during the school years, $t=0$, firms' best response decisions are given by (8) with $s=\sigma(\theta)$. And as remarked earlier, ceteris paribus, all individuals strictly prefer to be accepted rather than rejected by the group during the school years. However, Proposition 1 shows that the group is not happy to accept all types as members: the group strictly prefers to accept $\theta$ if and only if $F(\hat{\theta}(\delta) \mid \sigma(\theta))>F_{0}$ and is indifferent over accepting and rejecting whenever $F(\hat{\theta}(\delta) \mid \sigma(\theta))=F_{0}$.

Given Proposition 1, the firms' wage schedules (8) and the group's school year decision criterion (11) depend essentially on the individual educational investment strategy, $\sigma$. As in most signaling games, there are multiple equilibria possible, even within the class of peer pressure equilibria. One sort of equilibrium, however, surely does not exist here and that is any fully separating equilibria in which, for all types $\theta, \theta^{\prime}$, $\theta \neq \theta^{\prime}$ implies $\sigma(\theta) \neq \sigma\left(\theta^{\prime}\right){ }^{15}$

Say that a peer pressure equilibrium is fully separating if the equilibrium educational investment strategy is separating over all types $\theta>0$.

Proposition 2 There exist no fully separating peer pressure equilibria.

Figure 1 illustrates the intuition behind Proposition 2. The figure describes the net (peer pressure equilibrium) utility accruing to individual $\hat{\theta}(\delta)$ as a function of the chosen educational level under complete

\footnotetext{
${ }^{15}$ Strictly speaking, the notion of a separating strategy here should be confined to the set of types for which the utilitymaximizing education under complete information is strictly positive. Nothing in the analysis hinges on this and so, to avoid repeatedly having to make the appropriate qualifications, assume $\theta>0$ implies $\theta$ 's complete information maximizing choice of effort is not zero (whether or not $\theta$ is accepted by the group). Given (1), this is assured if

$$
\lim _{s \rightarrow 0}\left[y_{s}(s, 0)-v^{\prime}(1-s \mid \cdot)\right]>0 .
$$
}




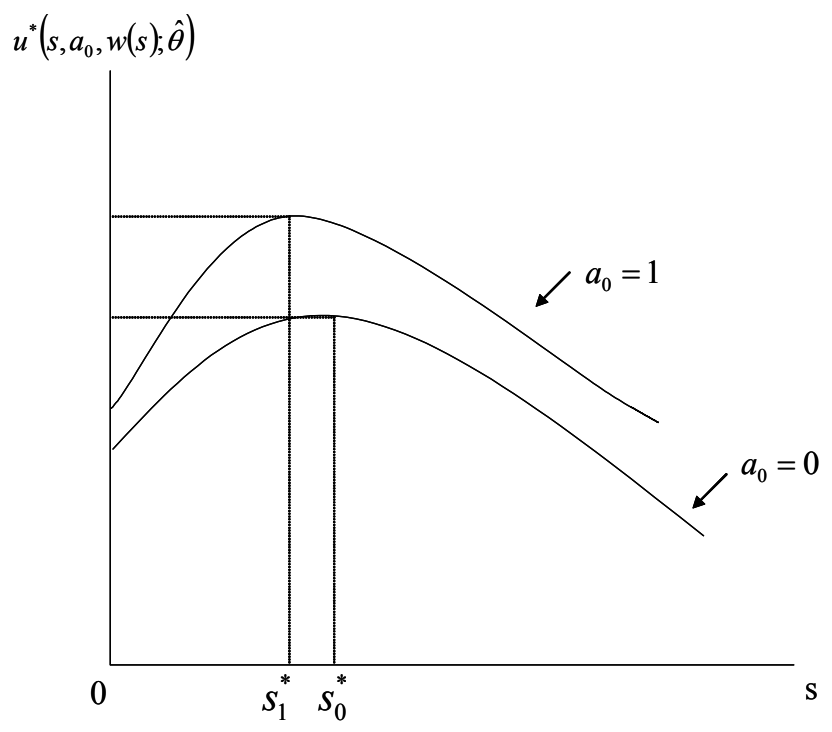

Figure 1: Payoffs for Marginal Type Under Complete Information

information, $u^{*}\left(s, a_{0}, w(s) ; \hat{\theta}\right)$ : at any given educational investment level $s$, the individual's net payoff is strictly greater being accepted than being rejected by the group and, further, in each case the net payoff is strictly concave in educational effort with an interior maximum. If there were a (fully) separating equilibrium, then there is no residual incomplete information and only those types $\theta \leq \hat{\theta}(\delta)$ would be accepted by the group. This implies that the boundary type $\hat{\theta}(\delta)$ has to be indifferent in equilibrium between being accepted with a wage $w$ and being rejected at a wage $w^{\prime}>w$, where the inequality follows from the marginal value of leisure being lower for rejected than for accepted individuals at any positive educational investment level. Therefore, as is clear from Figure 1, to support the equilibrium, the educational level inducing the wage $w$ must be strictly less than $\hat{\theta}(\delta)$ 's most preferred level of education conditional on group acceptance, $s_{1}^{*}$. But this is inconsistent with separation under which higher types must invest strictly more than they would under complete information so as to deter lower types from mimicking them (Appendix, Lemma 4).

Proposition 2 asserts that whenever there is peer pressure of the sort defined here, then necessarily the equilibrium involves some pooling of types. This still leaves a very large number of possibilities for equilibria, depending in part on the parameters in effect. Before considering any refinements, it is useful to establish some further general properties of any peer pressure equilibrium. For any pair of strategies $\left(\sigma, \alpha_{0}\right)$, denote the sets of types accepted and rejected by the group as, respectively, $A\left(\sigma, \alpha_{0}\right)=\left\{\theta: \alpha_{0}(\sigma(\theta))=1\right\}$ and $R\left(\sigma, \alpha_{0}\right)=\left\{\theta: \alpha_{0}(\sigma(\theta))=0\right\}$.

Proposition 3 Let $\left(\sigma^{*}, \alpha_{0}^{*}\right)$ be components of some peer pressure equilibrium. Then,

(1) $A\left(\sigma^{*}, \alpha_{0}^{*}\right)$ and $R\left(\sigma^{*}, \alpha_{0}^{*}\right)$ are convex with $\sup A\left(\sigma^{*}, \alpha_{0}^{*}\right)=\inf R\left(\sigma^{*}, \alpha_{0}^{*}\right)$;

(2) $R\left(\sigma^{*}, \alpha_{0}^{*}\right) \neq[0, \bar{\theta})$ implies there exists $\epsilon>0$ such that $\sigma^{*}(\theta)$ is constant on at least one of the intervals $\left(\inf R\left(\sigma^{*}, \alpha_{0}^{*}\right)-\epsilon, \inf R\left(\sigma^{*}, \alpha_{0}^{*}\right)\right)$ or $\left(\inf R\left(\sigma^{*}, \alpha_{0}^{*}\right), \inf R\left(\sigma^{*}, \alpha_{0}^{*}\right)+\epsilon\right)$; and 
(3) if $\sigma^{*}$ is separating on $\left(\inf R\left(\sigma^{*}, \alpha_{0}^{*}\right), \inf R\left(\sigma^{*}, \alpha_{0}^{*}\right)+\epsilon\right)$, inf $R\left(\sigma^{*}, \alpha_{0}^{*}\right) \geq \hat{\theta}(\delta)$.

The first claim of Proposition 3 is intuitive and follows easily from the monotonicity of any equilibrium educational strategy in type (Appendix, Lemma 3); and the intuition for the second claim is essentially identical to that supporting Proposition 2. The final claim of the result is suggestive: if types rejected by the group adopt a separating strategy, then necessarily the group accepts some types in equilibrium which they would reject under complete information. The implications of this for observed behavior in the longer run are discussed below.

Although the previous two results tell us a good deal about equilibria to the game, they do not, as already remarked, pin down exactly what can occur. Consequently, we consider further belief-based equilibrium refinements. As Banks (1990, p.16) observes, most of the usual refinements used for costly signaling games support identical equilibria when payoffs exhibit an appropriate monotonicity property, a property satisfied here where, other things being equal, higher wages are preferred to lower wages by all types (see also Cho and Sobel 1990). One such refinement much used in the literature is that of D1 equilibria (Banks and Sobel,1987; Cho and Kreps, 1987; Cho and Sobel 1990).

Loosely speaking, the D1 refinement requires out-of-equilibrium actions to be interpreted as being taken by those types having most to gain from the deviation relative to their payoffs from the candidate equilibrium, conditional on the uninformed agents best-responding to these beliefs. Equilibria supported by such out-of-equilibrium beliefs are called D1 equilibria, and the only D1 equilibrium to the canonic Spence job signaling model is the Riley (separating) equilibrium. The Riley equilibrium (Riley, 1979) is the unique efficient separating equilibrium defined by the initial condition whereby the lowest separating type adopts its complete information best educational investment level; all higher types choose the lowest educational levels consistent with separation and these strictly exceed their respective complete information decisions (Appendix, Lemma 4). Although it is not clear-cut that the separating equilibria to the Spence model constitute the "correct" predictions, they are certainly focal from an analytical perspective and have considerable substantive intuition; insofar as high type individuals can benefit from distinguishing themselves and are capable of so doing, then we might expect any equilibrium behavior to reflect this. Consequently, we look for separation in equilibrium educational investment strategies in the current model; in particular, the intuition for why we might expect separation in the Spence model applies a fortiori when considering the educational effort decisions of those rejected by the group during the school years. Thus, for both this reason and to facilitate comparisons across models, it seems reasonable to apply the D1 refinement to the current model. Further, 'acting white' is essentially about minorities pooling on low education levels, and D1 is the most hostile to pooling equilibrium (relative to other standard refinements).

Unfortunately, unlike for the Spence model, existence of D1 equilibria is not assured for all admissible parameterizations. Before stating the existence result, it is useful to identify some key properties of D1 equilibria conditional on their existence. For any type $\theta$, let $\sigma_{0}^{c}(\theta)$ denote the individual's utility maximizing choice of education assuming that $\theta$ is common knowledge and that the group rejects $\theta$ in the school years, 


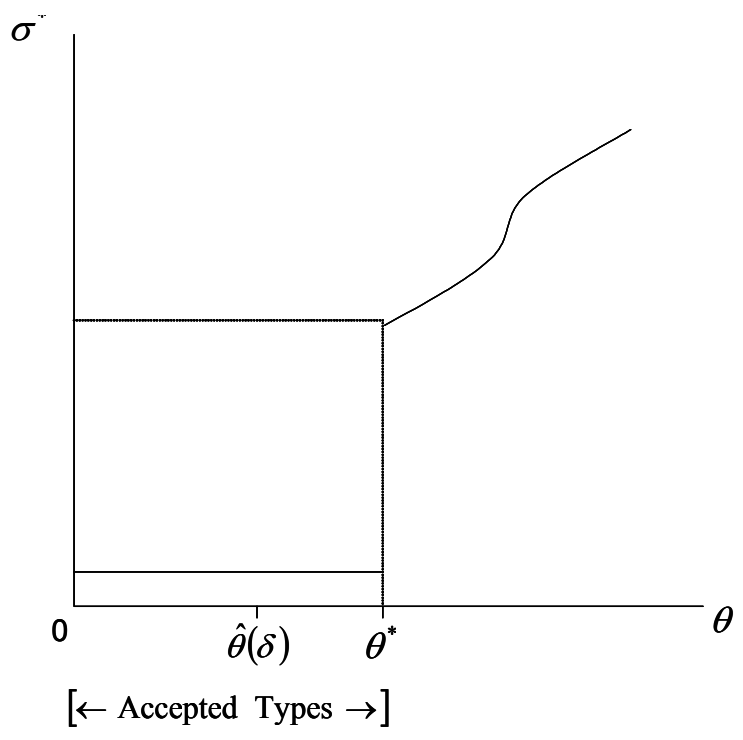

Figure 2: Typical D1 Peer Pressure Equilibrium Strategies, $\left(\sigma^{*}, \alpha_{0}^{*}\right)$

$a_{0}=0$.

Proposition 4 Let $\left(\sigma^{*}, \alpha_{0}^{*}\right)$ be components of a D1 peer pressure equilibrium. Then

(1) $\sigma^{*}(\theta)=\sigma^{*}\left(\theta^{\prime}\right)$ for all $\theta, \theta^{\prime} \in A\left(\sigma^{*}, \alpha_{0}^{*}\right)=\left[0, \theta^{*}\right], \theta^{*} \geq \hat{\theta}(\delta)$; and

(2) the restriction of $\sigma^{*}$ to the set of rejected types, $R\left(\sigma^{*}, \alpha_{0}^{*}\right)=\left(\theta^{*}, \bar{\theta}\right)$, is the unique efficient separating equilibrium strategy on $R\left(\sigma^{*}, \alpha_{0}^{*}\right)$ with initial condition, $\lim _{\eta \downarrow 0} \sigma^{*}\left(\theta^{*}+\eta\right)=\sigma_{0}^{c}\left(\theta^{*}\right)$.

In words, in any D1 peer pressure equilibrium the type-space can be partitioned into two intervals, $\left[0, \theta^{*}\right]$ and $\left(\theta^{*}, \infty\right)$, such that all types in $\left[0, \theta^{*}\right]$ pool on a common educational investment level and are accepted by the group, and all types greater than $\theta^{*}$ separate and are rejected by the group ${ }^{16}$. Figure 2 illustrates Proposition 4.

There is no guarantee that D1 peer pressure equilibria, when they exist, are unique. However, from the proposition and the monotonicity of payoffs in type at any given education, wage and group decision, a strictly positive educational investment by individuals accepted by the group, say $s_{1}>0$, can be supported in a D1 equilibrium only if the lowest accepted type is willing to choose $s_{1}$ rather than invest in education at some $s<s_{1}$. Such a condition is necessary because, under D1, any out-of-equilibrium downward deviation from $s_{1}$ is interpreted by the firms as coming surely from the lowest type, $\theta=0$. The lower is the discount factor, therefore, the more likely it is that peer pressure leads to pooling in the group on minimal educational achievement.

Proposition 4 says that if a D1 equilibrium exists, the educational investment strategy $\sigma^{*}$ must be separating over the set of rejected types, $R\left(\sigma^{*}, \alpha_{0}^{*}\right)$. By Proposition 3 , therefore, we must have the highest

\footnotetext{
${ }^{16}$ Fryer (2002) obtains a similar bi-polarization in the type space.
} 


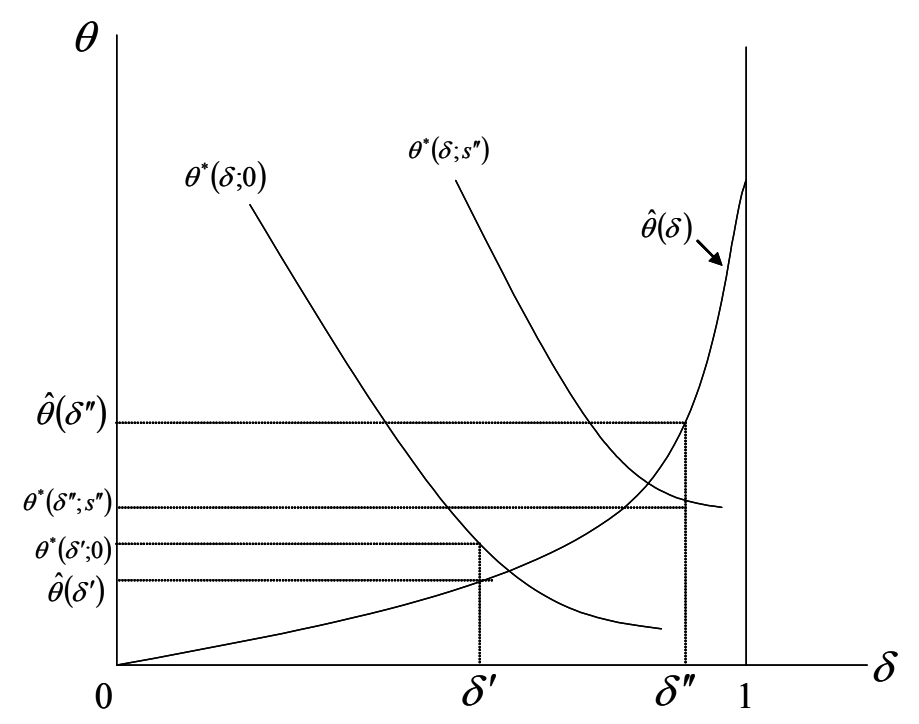

Figure 3: Existence of D1 Peer Pressure Equilibria

types accepted by the group using a pooling educational investment strategy in equilibrium and the highest accepted type can be no lower than $\hat{\theta}(\delta)$. But since D1 also rules out any discontinuities in the educational strategy $\sigma^{*}$ on $A\left(\sigma^{*}, \alpha_{0}^{*}\right)$, it is possible for there not to exist an educational level $s_{1}$ and an associated equilibrium wage $w\left(s_{1}\right)$ consistent both with $\hat{\theta}(\delta)$ and the lowest accepted type $\theta=0$ choosing $s_{1}$ at $w$. Thus there is no guarantee that D1 equilibria generally exist in the model. It turns out, however, that so long as individuals are sufficiently impatient, there is no problem.

Proposition 5 There are discount factors $\delta_{1}, \delta_{2}$ with $0<\delta_{1} \leq \delta_{2}<1$, such that D1 peer pressure equilibria exist if $\delta \leq \delta_{1}$ and only if $\delta \leq \delta_{2}$.

Proposition 5 says that D1 peer pressure equilibria surely exist for low discount factors $\left(\delta \leq \delta_{1}\right)$, might exist for some factors slightly higher $\left(\delta \in\left(\delta_{1}, \delta_{2}\right]\right)$, but surely do not exist for sufficiently high values of $\delta$ $\left(\delta>\delta_{2}\right)$. To get some intuition for the result, consider Figure 3. The downward sloping curves labeled $\theta^{*}(\delta ; s)$ describe, as a function of $\delta$, the type indifferent between pooling on $s \geq 0$ and being accepted by the group, and separating at his or her complete information best educational choice, say $s\left(\theta^{*}\right)$, and being rejected. Individual $\theta^{*}(\delta ; s)$, therefore, is the marginal equilibrium member of the group in an equilibrium in which all individuals accepted by the group choose education level $s$.

Suppose first that the discount factor is some $\delta^{\prime}<\delta_{1}$ and assume that accepted types in an equilibrium at $\delta^{\prime}$ pool on zero education; in this case, $\hat{\theta}\left(\delta^{\prime}\right)<\theta^{*}\left(\delta^{\prime} ; 0\right)$. Under the assumptions on beliefs defining D1, any deviation to a strictly positive out-of-equilibrium education level $s \in\left(0, s\left(\theta^{*}\right)\right)$ induces both firms and the group to infer the deviant's type as $\theta^{*}\left(\delta^{\prime} ; 0\right)$. It follows that by choosing to deviate to some education level $\epsilon>0$, the individual elicits an appropriately higher wage (a benefit) but is rejected by the group (a 
cost); in equilibrium, these responses deter $\theta^{*}\left(\delta^{\prime} ; 0\right)$ from such a deviation and the equilibrium satisfies D1.

Now consider some discount factor $\delta^{\prime \prime}>\delta_{2}$ and assume $s^{\prime \prime}>0$ is the highest educational level that can be sustained in any equilibrium at $\delta^{\prime \prime}$ in which all types $\left[0, \theta^{*}\left(\delta^{\prime \prime} ; s^{\prime \prime}\right)\right]$ are willing to pool and be accepted by the group. Given $s^{\prime \prime}>0$ the common wage paid to all accepted group members is strictly positive and so the indifferent marginal type here, $\theta^{*}\left(\delta ; s^{\prime \prime}\right)$, is strictly greater than the type $\theta^{*}(\delta ; 0)$. In this case, however, $\hat{\theta}\left(\delta^{\prime \prime}\right)>\theta^{*}\left(\delta^{\prime \prime} ; s^{\prime \prime}\right)$. Consequently, if this individual deviates to $s^{\prime \prime}+\epsilon$ and reveals her type, she earns a higher wage as before but is no longer rejected by the group; $\hat{\theta}\left(\delta^{\prime \prime}\right)>\theta^{*}\left(\delta^{\prime \prime} ; s^{\prime \prime}\right)$ implies the individual is a reliable group member so the group's best response conditional on learning her type is to continue to accept her. Therefore, such a deviation makes $\theta^{*}\left(\delta^{\prime \prime} ; s^{\prime \prime}\right)$ strictly better off implying the equilibrium at $\delta^{\prime \prime}$ cannot satisfy D1.

The argument for the proposition shows that discount rates such as $\delta^{\prime}$ and $\delta^{\prime \prime}$ surely exist. In fact, the proof for the existence of D1 equilibria at rates $\delta \leq \delta_{1}$ is constructive and establishes a stronger result:

Proposition 6 There is a discount factor $\delta_{1}>0$ such that a D1 peer pressure equilibrium exists in which all accepted types pool on zero educational investment if and only if $\delta \leq \delta_{1}$. Moreover, at each $\delta \leq \delta_{1}$ there is a unique "zero education" D1 equilibrium.

Although the proposition involves no claim that the "zero education" D1 equilibrium is the unique D1 equilibrium for $\delta \leq \delta_{1}$, the willingness of individuals to acquire any significant education in the school years is much diminished when the future is heavily discounted. That peer pressure incentives should drive equilibrium education to zero for group members is therefore not implausible. And even if higher types would, absent peer pressure, select significant education levels, the more costly it becomes for the lowest types to acquire education the more likely it becomes that the zero education D1 equilibrium is the only such equilibrium.

When $\delta>\delta_{2}$, insisting on the D1 refinement leads to equilibrium non-existence, as discussed above, and may also do so for $\delta>\delta_{1}$. However, there do exist many other (non-D1) peer pressure equilibria for these discount rates. Since a particularly appealing property of D1 equilibria when they exist is (we believe) that they demand separation over the set of types rejected by the peer group, we propose to look only at equilibria for high factors that preserve this property. And, to preserve some sort of continuity in the equilibrium selection, we also restrict attention to those separating segments defined by the initial condition that the least rejected type separates with its complete information best educational investment level. In view of Proposition 3(3), this gives the following refined set of equilibria.

Proposition 7 Suppose $\delta>\delta_{1}$ and no D1 equilibrium exists. Assume $\left(\sigma^{*}, \alpha_{0}^{*}\right)$ are components of a peer pressure equilibrium in which the restriction of $\sigma^{*}$ to the set of rejected types, $R\left(\sigma^{*}, \alpha_{0}^{*}\right)=\left(\theta^{*}, \bar{\theta}\right)$, is the unique efficient separating equilibrium strategy on $R\left(\sigma^{*}, \alpha_{0}^{*}\right)$ with initial condition, $\lim _{\eta \downarrow 0} \sigma^{*}\left(\theta^{*}+\eta\right)=\sigma_{0}^{c}\left(\theta^{*}\right)$. Then $\theta^{*} \geq \hat{\theta}(\delta)$ and there exists a type $\theta_{1}<\hat{\theta}(\delta)$ such that:

(1) $\theta_{1}>0$ and, for all $\theta, \theta^{\prime} \in\left(\theta_{1}, \theta^{*}\right), \sigma^{*}(\theta)=\sigma^{*}\left(\theta^{\prime}\right)=s_{1} \in\left(0, \sigma_{0}^{c}\left(\theta^{*}\right)\right)$; 

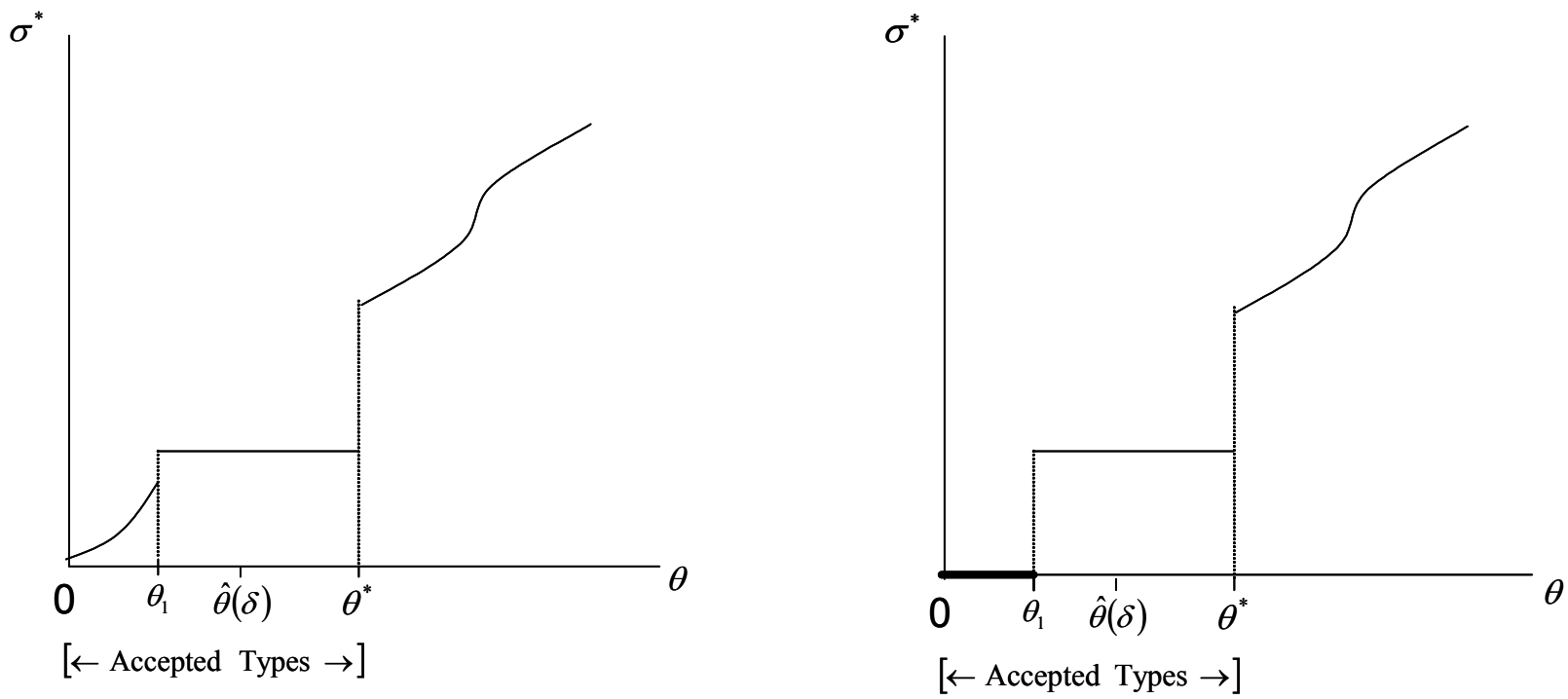

Figure 4: Peer Pressure Equilibria at a High Discount Factor

(2) either the restriction of $\sigma^{*}$ to the interval $\left[0, \theta_{1}\right)$ is separating, or there exists at least one other pooling segment in this interval; in both cases $\lim _{\theta \uparrow \theta_{1}} \sigma^{*}(\theta)<s_{1}$.

Proposition 7 leaves open a variety of possibilities for equilibrium education decisions for the lowest segment of types, $\left[0, \theta_{1}\right)$. There are two polar cases worth making explicit here: in the first, all types $\theta \in\left[0, \theta_{1}\right)$ separate; and in the second, all types $\theta \in\left[0, \theta_{1}\right)$ pool on a common educational investment. Figure 4 illustrates these alternatives.

The higher is the discount factor, the greater the long-run economic return to educational investment in the school years. It seems intuitive that any negative impact of peer pressure on individual effort in the school years is increasingly attenuated as people value the future more highly and the equilibrium predictions of the last three propositions reflect this intuition. When the discount factor is sufficiently low, peer pressure is effective and the desire to signal that one is an appropriate type for the group induces considerable underinvestment in education by many types, at least relative to the no-peer pressure separating equilibrium; only the highest types break away. The consequence is that group members all share a common minimal education level with the associated wage, while those rejected by the group are discretely more educated and earn distinctly higher incomes. For higher discount factors $\left(\delta>\delta_{1}\right)$, peer pressure is attenuated. At least for $\delta>\delta_{2}$, there has to be variation in the equilibrium distribution of educational efforts and economic returns among accepted group members. And since the critical type is increasing in the discount factor (Proposition 1 ), the group, other things being equal, accepts a broader set of types; thus we expect to find not only increasing variation in education and wage levels within the group as $\delta$ goes up, but also an increase in the type variation of accepted group members. Nevertheless peer pressure remains manifest in that the high types accepted by the group in the school years necessarily adopt the same educational effort strategy and 
continue to include types who will almost surely renege on the group and be rejected at some post-school year date. Formally, as illustrated in both Figures 2 and 4, Propositions 4 and 7 directly imply,

Corollary 1 Assume the restriction of the educational investment strategy in a peer pressure equilibrium to the set of rejected types, $R\left(\sigma^{*}, \alpha_{0}^{*}\right)$, is separating on that set. Then there (almost always) exists a strictly positive measure of types who are accepted by the group in the school years but who leave the group when first asked to contribute the high cost, $k>0$. And since educational investment is sunk, these types see no change in their earned income.

Consequently, the model predicts that we should observe the (relatively) high types leaving the group at some time, being rejected but continuing to work at their original, low, wage. In other words, following the school years there are, eventually, three sorts of individual in equilibrium: those accepted by the group who remain loyal and earn little; those originally accepted who eventually renege on the group and are rejected but continue to earn the low wage common to group members; and those rejected by the group in the school years who are significantly more educated and earn distinctly higher incomes than the other two sorts.

\section{A Benchmark: Tolerant Peer Group}

To provide a benchmark against which to juxtapose the results on peer pressure equilibria, we consider a peer group that exerts no pressure at all. To do this, suppose first that individual $\theta$ is an accepted member of the group in any post-school year $t \geq 1$ and assume Nature has revealed the contribution $\kappa_{t}$. Before any individual compliance decision for the period is taken, assume the individual makes a costless (i.e. cheap talk) statement about whether he or she intends to make the contribution $\kappa_{t}$ as required. Formally, for any type $\theta$ and realization $\kappa_{t}$, let $\tau\left(\kappa_{t}, \theta\right)$ describe the $\theta$ 's statement of intent, where $\tau\left(\kappa_{t}, \theta\right)=0$ [respectively, 1] means $\theta$ claims he or she does not [respectively, does] intend to contribute $\kappa_{t}$. It is not hard to see that since making the statement involves no costs to the individual irrespective of any realization $\left(\kappa_{t}, \theta\right)$, the preceding analysis of peer pressure equilibria is wholly unaffected; given the peer pressure strategy $[P 1]$, the possibility of cheap talk adds nothing. However, in groups devoid of peer pressure, the option to make cheap talk statements has bite.

A tolerant group is a peer group that adopts the following strategy:

[T1] : At $t=0$, choose $\alpha_{0}^{*}(s)=1$ all $s \in[0,1]$ and, for all $t \geq 1$, choose

$$
\alpha_{t}^{*}\left(h_{t-1}\right)=1 \Leftrightarrow\left[\tau\left(\kappa_{t}, \cdot\right)=1 \text { and }, \forall r=1, \ldots, t, h_{t-r}: d_{t-r}=\tau\left(\kappa_{t-r}, \cdot\right)\right] .
$$

In words, all individuals are accepted during the school years and any individual is accepted by the group in any period $t \geq 1$ so long as that individual states that he or she intends to make the period $t$ required contribution and has always honoured previous statements of intent. An individual is rejected in period $t$ alone if she states an intention not to contribute and has always done as she claimed she would in the 
past; and an individual is rejected for all periods if she has ever claimed an intention to contribute but then reneged on that claim. Tolerant groups are therefore more like trading partners than peer groups in which the opportunities for mutually profitable trade arrive stochastically and depend on an individual's type.

Given a tolerant group, define the (low) type $\theta^{T}$ to be that type who is indifferent between making every required contribution $\kappa_{t} \in\{0, k\}$ in every period and making only the contribution $\kappa_{t}=0$ in any period $t$. It is not hard to see that $\theta^{T}$ is independent of $\delta$. Consider the following strategy.

$$
[T 2]:\left\{\begin{array}{l}
\forall \theta \leq \theta^{T}, \tau\left(\kappa_{t}, \theta\right)=1 \& \psi_{t}^{*}\left(\kappa_{t}, \theta, h_{t-1}\right)=1 \text { for all } \kappa_{t} \\
\forall \theta>\theta^{T}, \tau\left(\kappa_{t}, \theta\right)=1 \& \psi_{t}^{*}\left(\kappa_{t}, \theta, h_{t-1}\right)=1 \text { iff } \kappa_{t}=0
\end{array}\right\} .
$$

Thus any type greater than $\theta^{T}$ only claims an intention to contribute when the required contribution is negligible; only the low types $\theta \leq \theta^{T}$ offer to make the high contribution. Given [T1], all claims under [T2] are honoured.

Call any equilibrium in which post-school year behavior is described by [T1] and [T2], a tolerant equilibrium.

Proposition 8 There exists a tolerant equilibrium if and only if $\delta \geq 1 /[1+\pi]$. Moreover, if there exists a tolerant equilibrium, then there exists a tolerant equilibrium in which all types separate in the school years.

Tolerant groups can survive in equilibrium only when individuals are sufficiently patient relative to the likelihood of having to contribute $k>0$ to the group. To see why the first condition is required, recall that statements of intent are cheap talk and the payoff for an individual who reneges on his stated intent under $[T 1]$, is identical to that of an accepted group member who defects under the peer pressure strategy $[P 1]$. Similarly, the payoff to an individual from making every contribution to the group is the same irrespective of whether the group is tolerant or subject to peer pressure. Consequently, a necessary condition for the existence of a tolerant group is that the value to an individual of always stating his or her intent honestly and so remaining in the group at least for some periods, is at least as big as the value of stating an intention to contribute $k$, reneging on this statement once accepted by the group for that period, but being rejected thereafter. This condition is that $\theta^{T} \leq \hat{\theta}(\delta)$ or, equivalently, that the joint restriction on $\delta$ and $\pi$ holds.

When individuals are relatively impatient, tolerant groups do not exist and some form of peer pressure is required to support the group. On the other hand, since tolerant groups have evident prima facie efficiency advantages over groups with peer pressure when tolerant equilibria exist, the obvious question is under what circumstances might peer effects be observed when the tolerant strategy [T1] is available? Let $\sigma(\theta)$ denote the peer pressure equilibrium educational strategy. Then we have

Proposition 9 Assume there exists a tolerant equilibrium. Then the group prefers peer pressure to tolerance if and only if

$$
F(\hat{\theta}(\delta) \mid \sigma(\theta)) \geq \frac{B k+F\left(\theta^{T}\right) b}{B k+b}
$$


In interpreting this result, it should be emphasized that the assumption of an anthropomorphized group makes the analysis here essentially one of the group's decision on the marginal prospective individual, the individual $\theta$. Consequently, without explicitly allocating the group's costs and benefits among existing members, virtually nothing can be said about all individuals' relative payoffs across the equilibria. The exception is that all types who separate and are rejected in the school years under peer pressure, are strictly better off with a tolerant group than otherwise. On the other hand, the proposition does show that peer pressure is more likely to be preferred when the benefits from an individual (i.e. b) are relatively high or when the distribution of types is distinctly skewed to the right and there is a high proportion of low types in the population.

\section{Conclusion}

Nearly 140 years after the abolishment of Chattel slavery, many economic indices exhibit drastic racial inequities. Black seventeen year olds read at a proficiency level of white thirteen year olds. Black male and female median earnings are substantially below their white counterparts in every education level except high school drop outs. Black employment rates are below whites for every occupational category, save Operators, Laborers, and service occupations. Ten percent of the black population age eighteen through twenty-four, working full time, live beneath the poverty threshold. Blacks constitute nearly sixty percent of those incarcerated, yet they barely make up twelve percent of the overall population (see Loury, 2002).

We consider one phenomenon that can help explain some of these disparities. The model here formalizes 'acting white' and explores its implications for individuals' education decisions during their school years. Together, two of the main results from the model yield the motivating stylized facts regarding 'acting white' and underachievement documented in the anthropology and sociology literatures: first, there exist no equilibria in which all types of individuals adopt distinct educational investment levels and, second, when individuals are not too patient, all equilibria satisfying a standard refinement involve a binary partition of the type space in which all types accepted by the group pool on a common low education level and all types rejected by the group separate at distinctly higher levels of education with correspondingly higher wages.

A third main result bears on the relative importance of peer pressure incentives. The formal result is that when individuals are very patient, the refined equilibria do not exist, but a fairly natural (at least in spirit) extension of the refinement predicts an increase in the variation of education levels within the group and an increase in the variance of types deemed acceptable by the group. Substantively, this translates into stating that the more those involved discount the future, the more acute peer pressure becomes and the more homogenous groups become. ${ }^{17}$ And it is worth remarking that the nondegenerate pooling property of high accepted types when individuals are more patient, illustrated in Figure 3, offers some justification for the Phelps (1972) assumption that the ability of minority workers is oftentimes perceived more noisily than

\footnotetext{
${ }^{17}$ Along these lines, the model also supports the intuitive comparative statics that peer pressure becomes more acute as the expected contribution level increases, and as the costs to the group of any individual defecting once admitted increase.
} 
that of similarly qualified majority workers. Suppose that minority individuals are subject to accusations of 'acting white' at school from which majority individuals are free. Then, in equilibrium, a minority individual and a majority individual can both achieve the same intermediate educational level but, whereas the latter can do so through separation, to avoid peer rejection the former can only do so through pooling with other minority types. Thus the two signals are indeed distinct in the way postulated by Milgrom and Oster (1987).

One further result worth emphasizing is that there always exist some types of individuals in equilibrium who 'succumb' to peer pressure and are accepted by the group in the school years, but who subsequently defect from the group when expected to make a high contribution. This last result predicts the existence of individuals who find themselves eventually rejected by their peers yet distinctly under-educated relative to what they would have been absent peer pressure. Consequently, since education is accrued in the model only during the school years, these individuals realize no change in their economic well-being once out of the group.

Along similar lines, it is not hard to check that if all firms experience a uniform upward shift in productivity (say, for all strictly positive $(s, \theta), d y(s, \theta)>0$ ) then (at least in a D1 equilibrium) the wages of those rejected by the group in the school years correspondingly increase and do so strictly more than any increase in wages of those accepted by the peer group; in particular, group members experience no economic improvement in a zero education equilibrium. Against this, the change in wages for rejected group members induces the marginal group member to break away in the school years and join those rejected by the group.

The qualitative character of the results is robust to changes in some of the assumptions. For instance, the assumption that required contributions from an individual to the group are either low or high is a convenience. Assuming instead that such contributions could take any one of a continuum of values induces a corresponding continuum of thresholds such that different types defect from the group at different cost levels. The main consequence of the change is that attrition from the group might occur during multiple periods, with the highest admitted types defecting earliest. All else, including the basic structure of equilibrium educational investment decisions, remains as described. On the other hand, the restriction on admissible wage contracts that might be offered by firms is important. Given the presumed technology, an employee whose type is not known surely at the time of employment will necessarily reveal his or her type after one day of work since de facto output and the employee's education are observed; there are then incentives for renegotiating the wage contract for future periods. Furthermore, since the group can observe any member's income, an individual's status as a group member or not can be affected. Incorporating wage renegotiation leads to considerable complications and the equilibrium consequences of admitting a full slate of contracts is as yet obscure.

Our model can be extended in a myriad of directions. The most obvious is to interact it with popular policy initiatives such as affirmative action, diversity programs, and educational interventions (i.e. head start). 


\section{Technical Appendix}

For any $r \in[0,1]$ and $a \in\{0,1\}$, define

$$
E_{(r)} v(1-\theta \tilde{\kappa} \mid a) \equiv r v(1 \mid a)+(1-r) v(1-\theta k \mid a) .
$$

Lemma 1 identifies a group member's best response to the peer pressure strategy $[P 1]$ conditional on being accepted by the group in the school years.

Lemma 10 Suppose $\sigma$ and the peer pressure strategy $[P 1]$ are played in an equilibrium and $\alpha_{0}(\sigma(\theta))=1$. Then for all $\delta \in(0,1)$, there exists a type $\widehat{\theta}(\delta)<1 / k$ such that $\widehat{\theta}(\delta)$ and the strategy $[P 2], \psi_{t}^{*} \equiv \psi_{t}^{*}[\widehat{\theta}(\delta)]$, is a best response to $[P 1]$, where

(1) $\theta \leq \widehat{\theta}(\delta) \Rightarrow \psi_{t}^{*}\left(\kappa_{t}, \theta, h_{t-1}\right)=1$ for all $\kappa_{t}$;

(2) $\theta>\widehat{\theta}(\delta) \Rightarrow\left[\psi_{t}^{*}\left(0, \theta, h_{t-1}\right)=1, \psi_{t}^{*}\left(k, \theta, h_{t-1}\right)=0\right]$.

Moreover, $\psi_{t}^{*}(\cdot)$ is the unique best response strategy to $[P 1]$ for all such $t>0$, up to whether $\widehat{\theta}(\delta)$ chooses 1 or 0 at $\kappa_{t}=k$; and $\widehat{\theta}(\delta)$ is strictly increasing in $\delta$ on $[0,1)$ with $\lim _{\delta \downarrow 0} \hat{\theta}(\delta)=0$.

Proof. Let $\theta$ be accepted by the group for the current period $t>0$ and assume the group uses the peer pressure strategy. It is, without loss of generality, convenient for the argument to follow to relabel time so the current (post-school years) period is indexed at zero. If $\kappa=0$ then $d_{t}=1$ and $d_{t}=0$ are observationally identical and there is no decision to be taken. So assume $\kappa=k$ and first note that, since $l_{t}(\cdot, \theta) \geq 0$ for all $\theta$, choosing $d_{t}=1$ is not a feasible action for any type $\theta>1 / k$, in which case $\psi_{t}\left(k, \theta, h_{t-1}\right)=0$ is the unique best response for such types. So assume $\theta \leq 1 / k$. Given $[P 1]$, the expected discounted payoff to $\theta$ from choosing to contribute at every cost $\kappa_{t}, d_{t}=1$ all $t$, is:

$$
U[1 ; k, \theta]=w+v(1-\theta k \mid 1)+\frac{\delta}{1-\delta}\left[w+E_{(\pi)} v(1-\theta \tilde{\kappa} \mid 1)\right]
$$

On the other hand, if $\kappa_{t}=k$ and $\theta$ chooses not to contribute $k>0$ today $(t)$ then, under the peer pressure strategy, $\theta$ receives the defect payoff for one period and is subsequently rejected by the group thereafter. So the expected payoff from choosing $d_{t}=0$ when $\kappa_{t}=k$ is:

$$
U[0 ; k, \theta]=w+v(1 \mid 1)+\frac{\delta}{1-\delta}[w+v(1 \mid 0)]
$$

Hence, comparing (12) and (13), $\theta$ 's best response decision depends on the difference,

$$
U[1 ; k, \theta]-U[0 ; k, \theta]=v(1-\theta k \mid 1)-v(1 \mid 1)+\frac{\delta}{1-\delta}\left[E_{(\pi)} v(1-\theta \tilde{\kappa} \mid 1)-v(1 \mid 0)\right] .
$$

Collecting terms we get

$$
U[1 ; k, \theta]\left\{\begin{array}{l}
\geq \\
<
\end{array}\right\} U[0 ; k, \theta] \Leftrightarrow E_{(\pi \delta)} v(1-\theta \tilde{\kappa} \mid 1)\left\{\begin{array}{l}
\geq \\
<
\end{array}\right\}(1-\delta) v(1 \mid 1)+\delta v(1 \mid 0) .
$$


Since $v(l(\cdot, \theta) \mid a)$ is strictly increasing in $l$,

$$
\lim _{\theta \rightarrow 0} E_{(\pi \delta)} v(1-\theta \tilde{\kappa} \mid 1)=v(1 \mid 1) .
$$

Therefore, for $\theta$ sufficiently small,

$$
E_{(\pi \delta)} v(1-\theta \tilde{\kappa} \mid 1)>[(1-\delta) v(1 \mid 1)+\delta v(1 \mid 0)]
$$

On the other hand, $l(\cdot, \theta) \geq 0$ implies

$$
\lim _{\theta \rightarrow \frac{j}{k}} E_{(\pi \delta)} v(1-\theta \tilde{\kappa} \mid 1)=\pi \delta v(1 \mid 1)
$$

and choosing $d_{t}=1$ is not a feasible action for $\theta>1 / k$. However, by $(7)$ and $\delta<1$,

$$
\pi \delta v(1 \mid 1) \leq \delta v(1 \mid 0)<[(1-\delta) v(1 \mid 1)+\delta v(1 \mid 0)] .
$$

Therefore, by monotonicity of $U\left[d_{t} ; \kappa, \theta\right]$ in $\theta$, there exists a unique type $\hat{\theta} \in(0,1 / k)$ such that $U[1 ; k, \hat{\theta}]=$ $U[0 ; k, \hat{\theta}]$. By monotonicity, $\widehat{\theta}(\delta)=\hat{\theta}$ is the required type. That is,

$$
E_{(\pi \delta)} v(1-\widehat{\theta}(\delta) \tilde{\kappa} \mid 1)-[(1-\delta) v(1 \mid 1)+\delta v(1 \mid 0)] \equiv 0 .
$$

Since $\widehat{\theta}(\delta)<1 / k$, implicit differentiation through (15) with respect to $\delta$ yields $\hat{\theta}(\delta)$ strictly increasing in $\delta$ on $(0,1)$. And finally, that $\lim _{\delta \downarrow 0} \hat{\theta}(\delta)=0$ follows directly from taking $\delta \rightarrow 0$ in (15); and the uniqueness claim is apparent from the existence argument.

Hereafter, assume (as specified in statement (1) of Lemma 3) that an individual of type $\widehat{\theta}(\delta)$ always chooses to contribute when indifferent.

Lemma 1 identifies an individual $\theta$ 's best response $\psi_{t}^{*}$, to the peer pressure strategy, contingent on being an accepted member of the group at the start of any period $t \geq 1$. Lemma 2 identifies the conditions under which the peer pressure strategy is a best response to $\psi_{t}^{*}$.

Lemma 11 Let $\sigma(\theta)$ be an individual $\theta$ 's educational investment decision at $t=0$. Then in any peer pressure equilibrium the group accepts the individual during the school years if

$$
F(\hat{\theta}(\delta) \mid \sigma(\theta))>\frac{[(1-\pi) B k-\pi b](1-\gamma)}{[b+(1-\gamma) B k](1-\pi)}
$$

and only if this inequality is weak.

Proof. By assumption, rejecting the individual during the school years, $a_{0}(\sigma(\theta))=0$, implies a zero payoff to the group thereafter. On the other hand, by Lemma 1, accepting the individual in $t=0$ yields an expected payoff to the group of $b>0$ in each period if the individual is type $\theta \leq \hat{\theta}(\delta)$ but not if $\theta>\hat{\theta}(\delta)$. Suppose the group accepts $\theta>\hat{\theta}(\delta)$. Then with probability $1-\pi$ the group receives $-B k<0$ in $t=1$ following which the group rejects $\theta$ and receives zero thereafter, and with probability $\pi$ the group receives $b$ and $\theta$ 
remains an accepted group member, in which case the same lottery confronts the group for $t=2$; and so on. Discounting back to $t=0$, the expected payoff to the group of accepting individual $\theta>\hat{\theta}(\delta)$ in the school years sums to

$$
\frac{[\pi b-(1-\pi) B k] \gamma}{1-\pi \gamma}
$$

Hence, in any peer pressure equilibrium the expected value to the group of accepting an individual with observed educational effort $\sigma(\theta)$ in the school years is,

$$
\begin{aligned}
& z\left[\left(\sigma(\theta),\left\{\psi_{t}^{*}\right\}_{t=1}^{\infty}\right),\left(1,\left\{\alpha_{t}^{*}\right\}_{t=1}^{\infty}\right), w\right] \\
= & F(\hat{\theta}(\delta) \mid \sigma(\theta)) \frac{\gamma b}{1-\gamma}+[1-F(\hat{\theta}(\delta) \mid \sigma(\theta))] \frac{\gamma[\pi b-(1-\pi) B k]}{1-\pi \gamma} .
\end{aligned}
$$

Therefore, the group accepts an individual with educational investment $\sigma(\theta)$ in the school years, i.e. $\alpha_{0}(\sigma(\theta))=$ 1 , only if $z\left[\left(\sigma(\theta),\left\{\psi_{t}^{*}\right\}_{t=1}^{\infty}\right),\left(1,\left\{\alpha_{t}^{*}\right\}_{t=1}^{\infty}\right), w\right] \geq 0$. On collecting terms and rearranging,

$$
\begin{aligned}
z\left[\left(\sigma(\theta),\left\{\psi_{t}^{*}\right\}_{t=1}^{\infty}\right),\left(1,\left\{\alpha_{t}^{*}\right\}_{t=1}^{\infty}\right), w\right] & \geq 0 \Leftrightarrow \\
F(\hat{\theta}(\delta) \mid \sigma(\theta)) & \geq \frac{[(1-\pi) B k-\pi b](1-\gamma)}{[b+(1-\gamma) B k](1-\pi)} .
\end{aligned}
$$

as required for necessity. Furthermore, by (7), the RHS of the inequality lies strictly between zero and one. That the group accepts surely whenever the preceding inequalities are strict follows from sequential rationality.

For future reference, recall

$$
F_{0} \equiv \frac{[(1-\pi) B k-\pi b](1-\gamma)}{[b+(1-\gamma) B k](1-\pi)}
$$

for the minimal belief necessary for the group to accept an individual into the group.

Proof of Proposition 1 The proposition follows directly from Lemmas 1 and 2.

We now confirm some familiar properties of equilibrium strategies $\sigma$. By (6), no firm will employ an individual without any education. Consequently, an individual $\theta$ 's expected payoff (9) from choosing effort level $\sigma(\theta)>0$ in some peer pressure equilibrium is

$$
\begin{aligned}
& u\left[\left(\sigma(\theta),\left\{\psi_{t}^{*}\right\}_{t=1}^{\infty}\right),\left(\alpha_{0}^{*},\left\{\alpha_{t}^{*}\right\}_{t=1}^{\infty}\right), w ; \theta\right]= \\
& \quad v\left(1-\sigma(\theta) \mid \alpha_{0}^{*}(\sigma(\theta))\right)-c(\sigma(\theta), \theta)+\frac{\delta}{1-\delta} w\left(\sigma(\theta),\left.F\right|_{\sigma(\theta)}\right)+V\left(\alpha_{0}^{*}(\sigma(\theta)) ; \theta\right)
\end{aligned}
$$

where $V\left(\alpha_{0}^{*}(\sigma(\theta)) ; \theta, \delta\right) \equiv \sum_{t=1}^{t=\infty} \delta^{t} E\left[v\left(l_{t}\left(\psi_{t}^{*}\left(\kappa_{t}, \theta, h_{t-1}\right), \theta\right) \mid \alpha_{t}^{*}\left(h_{t-1}\right)\right)\right]$ depends on $\sigma(\theta)$ only insofar as $\theta^{\prime}$ s effort choice influences whether $\theta$ is accepted by the group in the school years. In particular, if $\alpha_{0}^{*}(\sigma(\theta))=0$ then $V(0 ; \theta, \delta)=\delta v(1 \mid 0) /(1-\delta)$.

Lemma 12 Consider any pair of types $\theta^{\prime}, \theta^{\prime \prime}$ and let $\sigma$ be any equilibrium educational investment strategy. Suppose $\alpha_{0}\left(\sigma\left(\theta^{\prime}\right)\right)=\alpha_{0}\left(\sigma\left(\theta^{\prime \prime}\right)\right)$. Then $\theta^{\prime}<\theta^{\prime \prime}$ implies $\sigma\left(\theta^{\prime}\right) \leq \sigma\left(\theta^{\prime \prime}\right)$. 
Proof. Write $s^{\prime} \equiv \sigma\left(\theta^{\prime}\right), w^{\prime} \equiv w\left(\sigma\left(\theta^{\prime}\right),\left.F\right|_{\sigma\left(\theta^{\prime}\right)}\right)$, and so forth. Then for the pair of types $\theta^{\prime}, \theta^{\prime \prime}$, incentive compatibility requires

$$
\begin{aligned}
u\left[\left(s^{\prime}, \cdot\right),\left(\alpha_{0}, \cdot\right), w^{\prime} ; \theta^{\prime}\right] & \geq u\left[\left(s^{\prime \prime}, \cdot\right),\left(\alpha_{0}, \cdot\right), w^{\prime \prime} ; \theta^{\prime}\right], \\
u\left[\left(s^{\prime \prime}, \cdot\right),\left(\alpha_{0}, \cdot\right), w^{\prime \prime} ; \theta^{\prime \prime}\right] & \geq u\left[\left(s^{\prime}, \cdot\right),\left(\alpha_{0}, \cdot\right), w^{\prime} ; \theta^{\prime \prime}\right] .
\end{aligned}
$$

Substituting from (16), the preceding inequalities can be written equivalently

$$
\begin{aligned}
{\left[v\left(1-s^{\prime} \mid \alpha_{0}\right)-c\left(s^{\prime}, \theta^{\prime}\right)\right]-\left[v\left(1-s^{\prime \prime} \mid \alpha_{0}\right)-c\left(s^{\prime \prime}, \theta^{\prime}\right)\right] } & \geq \frac{\delta\left(w^{\prime \prime}-w^{\prime}\right)}{1-\delta}, \\
{\left[v\left(1-s^{\prime} \mid \alpha_{0}\right)-c\left(s^{\prime}, \theta^{\prime \prime}\right)\right]-\left[v\left(1-s^{\prime \prime} \mid \alpha_{0}\right)-c\left(s^{\prime \prime}, \theta^{\prime \prime}\right)\right] } & \leq \frac{\delta\left(w^{\prime \prime}-w^{\prime}\right)}{1-\delta}
\end{aligned}
$$

which together yield,

$$
c\left(s^{\prime \prime}, \theta^{\prime}\right)-c\left(s^{\prime}, \theta^{\prime}\right) \geq c\left(s^{\prime \prime}, \theta^{\prime \prime}\right)-c\left(s^{\prime}, \theta^{\prime \prime}\right) .
$$

And since $c_{s \theta}(s, \theta)<0$ by (1), $\theta^{\prime}<\theta^{\prime \prime}$ and the inequality jointly imply $s^{\prime} \leq s^{\prime \prime}$, as claimed.

Thus educational choice is monotonic in type, both among group members and among those rejected by the group. The next result confirms the inefficiency inherent in separating equilibria, should they exist. For any type $\theta$, let $\sigma_{a_{0}}^{c}(\theta)$ denote the individual's utility maximizing choice of educational effort assuming $\theta$ is common knowledge and group membership is fixed at $a_{0} \in\{0,1\}$.

Lemma 13 Let $I \subseteq[0, \bar{\theta})$ be any open interval, and assume $\sigma$ is a separating equilibrium strategy on $I$. Suppose $\alpha_{0}(\sigma(\theta))=a_{0} \in\{0,1\}$ is constant on $I$. Then for all $\theta \in I, \sigma(\theta)>\sigma_{a_{0}}^{c}(\theta)$.

Proof. By Lemma 3 and (e.g.) Royden (1968), since $\alpha_{0} \in\{0,1\}$ is constant in $\sigma(\theta)$ on $I, \sigma(\cdot)$ is differentiable in $\theta$ almost everywhere on this interval. And $\alpha_{0}$ invariant also gives $V\left(\alpha_{0}(\sigma(\theta)) ; \theta, \delta\right)=V\left(\alpha_{0} ; \theta, \delta\right)$ all $\theta \in I$. Moreover, since $\sigma(\theta)$ is separating and so (by definition) fully reveals $\theta$, (8) implies $w\left(\sigma(\theta),\left.F\right|_{\sigma(\theta)}\right)=$ $y(\sigma(\theta), \theta)$. Consequently, local incentive compatibility and $\alpha_{0}(\cdot)=a_{0}$ invariant imply that for all $\theta \in I$,

$$
\left.\frac{d}{d \theta^{\prime}}\left[v\left(1-\sigma\left(\theta^{\prime}\right) \mid a_{0}\right)-c\left(\sigma\left(\theta^{\prime}\right), \theta\right)+\frac{\delta}{1-\delta} y\left(\sigma\left(\theta^{\prime}\right), \theta^{\prime}\right)\right]\right|_{\theta^{\prime}=\theta}=0 .
$$

Doing the calculus, we obtain

$$
\left.\frac{d \sigma}{d \theta^{\prime}}\right|_{\theta^{\prime}=\theta}=\frac{\delta y_{\theta}}{\left[(1-\delta)\left(v^{\prime}\left(\cdot \mid a_{0}\right)+c_{s}\right)-\delta y_{s}\right]},
$$

where the arguments of the functions are suppressed. By assumption, $\sigma$ is a separating equilibrium strategy on $I$ and so Lemma 3 requires $d \sigma(\theta) / d \theta>0$ almost everywhere on the interval. Hence, (17) implies

$$
\left.\left[(1-\delta)\left(v^{\prime}\left(\cdot \mid a_{0}\right)+c_{s}\right)-\delta y_{s}\right]\right|_{s=\sigma(\theta)}>0 .
$$

Now by definition, $\sigma_{a_{0}}^{c}(\theta)$ is a solution to the first order condition

$$
\frac{d}{d s}\left[v\left(1-s \mid a_{0}\right)-c(s, \theta)+\frac{\delta}{1-\delta} y(s, \theta)\right]=0 .
$$


So, because the second order condition holds under the maintained assumptions, $\sigma_{a_{0}}^{c}(\theta)$ uniquely solves

$$
\left.\left[\delta y_{s}-(1-\delta)\left(v^{\prime}\left(\cdot \mid a_{0}\right)+c_{s}\right)\right]\right|_{s=\sigma_{a_{0}}^{c}(\theta)}=0
$$

The Lemma now follows by comparing (18) with (19).

Remark 1 Given (3), inspection of (17) and (19) yields that under complete information - either through use of a separating strategy or because types are common knowledge ex ante - all $\theta>0$ individuals invest strictly more effort in education if they are rejected by the group than if they are accepted.

To save on notation, for any education strategy $\sigma$, group action $a_{0}$, and type $\theta$ let

$$
\mathcal{U}\left(\sigma(\theta), a_{0} ; \theta, \delta\right) \equiv v\left(1-\sigma(\theta) \mid a_{0}\right)-c(\sigma(\theta), \theta)+\frac{\delta}{1-\delta} w\left(\sigma(\theta),\left.F\right|_{\sigma(\theta)}\right) .
$$

Proof of Proposition 2 Suppose the contrary and let $\sigma$ be an equilibrium separating strategy, so $w\left(\sigma(\theta),\left.F\right|_{\sigma(\theta)}\right)=$ $y(\sigma(\theta), \theta)$ for all $\theta$. By Lemma 2, there exists (in equilibrium) some type $\theta^{\circ} \leq \hat{\theta}(\delta)$ such that $\alpha_{0}(\sigma(\theta))=1$ if and only if $\theta \leq \theta^{\circ}$; write $\sigma(\theta)=\sigma_{0}(\theta)$ if $\theta>\theta^{\circ}$, and write $\sigma(\theta)=\sigma_{1}(\theta)$ if $\theta \leq \theta^{\circ}$. By continuity of individual utility, $\theta^{\circ}$ must be indifferent between being accepted and being rejected by the group in the school years. Using (16) and $\sigma$ separating, $\theta^{\circ}$ is indifferent only if

$$
\mathcal{U}\left(\sigma_{0}\left(\theta^{\circ}\right), 0 ; \theta^{\circ}, \delta\right)+V\left(0 ; \theta^{\circ}, \delta\right)=\mathcal{U}\left(\sigma_{1}\left(\theta^{\circ}\right), 1 ; \theta^{\circ}, \delta\right)+V\left(1 ; \theta^{\circ}, \delta\right) .
$$

Because all $\theta>0$ are employed in a separating equilibrium, definition of $\hat{\theta}(\delta)$ in the proof to Lemma 1 [see (14) and (15)] implies

$$
V(1 ; \theta, \delta)-V(0 ; \theta, \delta) \geq v(1 \mid 1)-v(1-\theta k \mid 1)>0
$$

for all $\theta \leq \hat{\theta}(\delta)$. Hence, (20) implies

$$
\mathcal{U}\left(\sigma_{0}\left(\theta^{\circ}\right), 0 ; \theta^{\circ}, \delta\right)-\mathcal{U}\left(\sigma_{1}\left(\theta^{\circ}\right), 1 ; \theta^{\circ}, \delta\right)>0 .
$$

And under the maintained assumptions, (21) in turn requires $\sigma_{0}\left(\theta^{\circ}\right)>\sigma_{1}\left(\theta^{\circ}\right)$. By Lemma 4 and Remark 2,

$$
\sigma_{0}\left(\theta^{\circ}\right)>\sigma_{0}^{c}\left(\theta^{\circ}\right)>\sigma_{1}^{c}\left(\theta^{\circ}\right) \geq 0
$$

But since $\mathcal{U}\left(s, a_{0} ; \theta^{\circ}, \delta\right)$ is strictly concave in $s$ for each $a_{0}$ and $v(l \mid 0)<v(l \mid 1)$ all $l>0,(21)$ and (22) imply $\sigma_{1}^{c}\left(\theta^{\circ}\right) \geq \sigma_{1}\left(\theta^{\circ}\right)$ which contradicts Lemma 4 .

Proof of Proposition 3 Since the prior cdf $F$ is smooth with support $[0, \bar{\theta})$, claim (1) follows directly from Lemmas 2 and 3. To establish the second claim, assume $R\left(\sigma^{*}, \alpha_{0}^{*}\right) \neq[0, \bar{\theta})$ and let $\theta^{m} \equiv \inf R\left(\sigma^{*}, \alpha_{0}^{*}\right)$. If there is no $\epsilon>0$ with $\sigma^{*}(\theta)$ constant on at least one of the intervals $\left(\theta^{m}-\epsilon, \theta^{m}\right)$ or $\left(\theta^{m}, \theta^{m}+\epsilon\right)$, then Lemma 3 implies $\sigma^{*}(\theta)$ must be separating on $\left(\theta^{m}-\epsilon^{\prime}, \theta^{m}+\epsilon^{\prime}\right)$ for some $\epsilon^{\prime}>0$. By definition of $\theta^{m}$, $\lim _{\eta \downarrow 0} \alpha_{0}^{*}\left(\sigma^{*}\left(\theta^{m}-\eta\right)\right)=1$ and $\lim _{\eta \downarrow 0} \alpha_{0}^{*}\left(\sigma^{*}\left(\theta^{m}+\eta\right)\right)=0$. But since $\theta^{m}$ must be indifferent between being accepted and being rejected by the group, the argument for Proposition 2 implies that either inf $R\left(\sigma^{*}, \alpha_{0}^{*}\right)<$ 
$\theta^{m}-\epsilon^{\prime}$ or $\inf R\left(\sigma^{*}, \alpha_{0}^{*}\right)>\theta^{m}+\epsilon^{\prime}$, a contradiction in both cases. Finally, suppose $\sigma^{*}$ is separating on the interval $\left(\theta^{m}, \theta^{m}+\epsilon\right)$ with $\epsilon>0$ and $\theta^{m} \equiv \inf R\left(\sigma^{*}, \alpha_{0}^{*}\right)<\hat{\theta}(\delta)$. Then there exist $\eta>0$ such that $\theta^{m}+\eta<\hat{\theta}(\delta)$; by Lemma 2 , therefore, $\alpha_{0}^{*}\left(\sigma^{*}\left(\theta^{m}+\eta\right)\right)=1$, contradicting $\theta^{m}+\eta \in R\left(\sigma^{*}, \alpha_{0}^{*}\right)$ and proving (3).

Proof of Proposition 4 By Proposition 2, $\sigma^{*}$ cannot be separating on $[0, \bar{\theta})$ and, by $(1), \sigma^{*}(\theta)<1$ for all $\theta \in[0, \bar{\theta})$ in any equilibrium. By Proposition $3, R\left(\sigma^{*}, \alpha_{0}^{*}\right)$ is an interval $\left(\theta^{*}, \bar{\theta}\right)$; let $\lim _{\eta \downarrow 0} \sigma^{*}\left(\theta^{*}+\eta\right)=s^{*}$. By Cho \& Sobel (1990, Lemma 4.1(d)), if the equilibrium is D1 then it is supported by beliefs under which, for any out-of-equilibrium signal $s^{\prime}>s^{*}$, the group's best response is likewise $\alpha_{0}\left(s^{\prime}\right)=0$. Consequently, since $s^{*}<1$, we can apply Cho \& Sobel (1990, Proposition 4.1) to yield pooling on $R\left(\sigma^{*}, \alpha_{0}^{*}\right)$ inconsistent with D1. Therefore, if $\sigma^{*}$ is part of a D1 peer pressure equilibrium, $\sigma^{*}$ must be separating on $R\left(\sigma^{*}, \alpha_{0}^{*}\right)$, proving the first part of (2). Proposition 3 now implies there exists some $\theta^{\prime}<\theta^{*}$ such that $\sigma^{*}(\theta)=\bar{s}$ for all $\theta \in\left[\theta^{\prime}, \theta^{*}\right] \subseteq A\left(\sigma^{*}, \alpha_{0}^{*}\right)$ and $\theta^{*} \geq \hat{\theta}(\delta)$. To complete the argument for (1), we have to show $\theta^{\prime}=0$.

Suppose $\sigma^{*}(\theta)$ is not constant in $\theta$ on $A\left(\sigma^{*}, \alpha_{0}^{*}\right)=\left[0, \theta^{*}\right]$. Then by Lemma 3 there exists an equilibrium educational investment level $s<\bar{s}$ such that $\sigma^{*}(\theta)=s$ for some $\theta \in A\left(\sigma^{*}, \alpha_{0}^{*}\right)$ and $\sigma^{*}(\theta) \in(s, \bar{s})$ for no $\theta \in[0, \bar{\theta})$. Furthermore, Lemma 3 and (equilibrium) $\mathcal{U}$ continuous in educational investment for a fixed group decision $a_{0}$ imply there exists some type $\theta^{\circ} \leq \theta^{\prime}$ with $\mathcal{U}\left(s, 1 ; \theta^{\circ}, \delta\right)=\mathcal{U}\left(\bar{s}, 1 ; \theta^{\circ}, \delta\right)$. But then the argument for Cho \& Sobel (1990, Proposition 4.1) can again be applied, mutatis mutandis, to derive a contradiction with D1. Hence, if $\sigma^{*}$ is part of a D1 peer pressure equilibrium, $\theta^{\prime}=0$ and $\sigma^{*}$ must be pooling on $A\left(\sigma^{*}, \alpha_{0}^{*}\right)$ with $\sigma^{*}(\theta)=\bar{s}$ for all $\theta \in A\left(\sigma^{*}, \alpha_{0}^{*}\right)$.

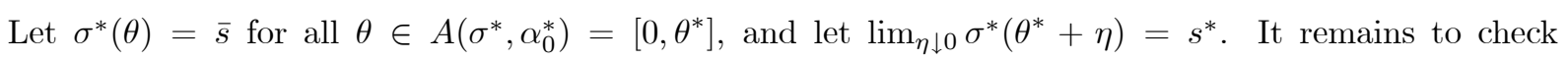
$s^{*}=\sigma_{0}^{c}\left(\theta^{*}\right)$. By continuity,

$$
\mathcal{U}\left(s^{*}, 0 ; \theta^{*}, \delta\right)+V\left(0 ; \theta^{*}\right)=\mathcal{U}\left(\bar{s}, 1 ; \theta^{*}, \delta\right)+V\left(1 ; \theta^{*}\right)
$$

By Lemma 4 and concave preferences in $s, s^{*} \geq \sigma_{0}^{c}\left(\theta^{*}\right)>\bar{s}$. Suppose $s^{*}>\sigma_{0}^{c}\left(\theta^{*}\right)$ and consider the out-ofequilibrium deviation, $\sigma\left(\theta^{*}\right)=\sigma_{0}^{c}\left(\theta^{*}\right)$. Since $\alpha_{0}^{*}\left(\sigma^{*}(\theta)\right)=0$ for all $\theta>\theta^{*}$ and $\theta^{*} \geq \hat{\theta}(\delta)$, Lemma 2 implies (generically) the group would reject $\theta^{*}$ conditional on identifying $\theta^{*}$ and $\sigma\left(\theta^{*}\right) \geq \bar{s}$. Thus, Cho \& Sobel (1990, Lemma $4.1(\mathrm{~d})$ ) yields that both firms and the group put probability zero on the deviation being sent by any type $\theta<\theta^{*}$; and definition of $\sigma_{0}^{c}\left(\theta^{*}\right)$ implies all probability weight is placed on $\theta^{*}$. But since $\mathcal{U}\left(s^{*}, 0 ; \theta^{*}, \delta\right)<$ $\mathcal{U}\left(\sigma_{0}^{c}\left(\theta^{*}\right), 0 ; \theta^{*}, \delta\right)$, continuity implies, $\lim _{\eta \downarrow 0} \mathcal{U}\left(\sigma^{*}\left(\theta^{*}+\eta\right), 0 ; \theta^{*}+\eta, \delta\right)<\lim _{\eta \downarrow 0} \mathcal{U}\left(\sigma_{0}^{c}\left(\theta^{*}\right), 0 ; \theta^{*}+\eta, \delta\right)$. Hence, for sufficiently small $\eta>0, \theta^{*}+\eta$ strictly prefers to deviate to $\sigma_{0}^{c}\left(\theta^{*}\right)$, contradicting $s^{*}>\sigma_{0}^{c}\left(\theta^{*}\right)$ in a D1 equilibrium.

Proof of Proposition 5 Fix $\delta \in(0,1)$ arbitrarily and write $\hat{\theta}(\delta) \equiv \hat{\theta}$. By Proposition 4, it suffices to consider educational investment strategies of the following form: for any $\theta^{\prime} \in[\hat{\theta}, \bar{\theta})$, define the strategy $\sigma\left(\cdot \mid \theta^{\prime}\right)$ such that, for all $\theta \leq \theta^{\prime}, \sigma\left(\theta \mid \theta^{\prime}\right)=s$ and, for all $\theta \in\left(\theta^{\prime}, \bar{\theta}\right), \sigma\left(\cdot \mid \theta^{\prime}\right) \equiv \sigma_{a}\left(\cdot \mid \theta^{\prime}\right)$ is the separating strategy 
defined by the unique solution to (17) satisfying initial condition, $\lim _{\eta \downarrow 0} \sigma_{a}\left(\theta^{\prime}+\eta \mid \theta^{\prime}\right)=\sigma_{a}^{c}\left(\theta^{\prime}\right)$. Let

$$
\omega\left(s ; \theta^{\prime}\right) \equiv \frac{1}{F\left(\theta^{\prime}\right)} \int_{0}^{\theta^{\prime}} y(s, \theta) d F(\theta)
$$

and note that, for any $\theta>\theta^{\prime}, w\left(\sigma_{a}\left(\theta \mid \theta^{\prime}\right),\left.F\right|_{\sigma_{a}(\cdot)}\right)=y\left(\sigma_{a}\left(\theta \mid \theta^{\prime}\right), \theta\right)>0$; write $w^{\operatorname{sep}}\left(\theta ; \theta^{\prime}\right) \equiv y\left(\sigma_{a}\left(\theta \mid \theta^{\prime}\right), \theta\right)$. With these preliminaries, consider the sufficiency argument.

(Sufficiency) The proof is by construction: we first show there exists a D1 equilibrium at $\delta$ in which all accepted types pool on $s=0$ if, and only if, $\hat{\theta}$ weakly prefers adopting the pooling strategy $\sigma(\theta \mid \hat{\theta})=0$ to the separating strategy $\sigma_{0}(\theta \mid \hat{\theta})=\sigma_{0}^{c}(\hat{\theta})$; we then argue that $\hat{\theta}(\delta)$ weakly prefers this pooling strategy if and only if $\delta \leq \delta_{1}$. So set $\theta^{\prime}=\hat{\theta}(\delta) \equiv \hat{\theta}$ and choose $s=0$; then by (6) and $(8), \omega(s ; \hat{\theta}) \equiv w(0, \cdot)=0$. By Lemma $2, \alpha_{0}(0)=1$ and, by Lemma 2 and $\sigma_{a}(\cdot \mid \hat{\theta})$ continuous on $(\hat{\theta}, \bar{\theta}), \alpha_{0}\left(\sigma_{a}^{c}(\hat{\theta})\right)=a=0$. Writing $\sigma_{0}^{c}(\hat{\theta})=\hat{s}$ and suppressing the arguments identifying post-school year strategies, the payoffs to $\hat{\theta}$ for using the respective strategies, $u\left[s, a_{0}, w ; \hat{\theta}\right]$, are:

$$
u[0,1,0 ; \hat{\theta}]=v(1 \mid 1)+\frac{\delta}{1-\delta} E_{(\pi)} v(1-\hat{\theta} \tilde{\kappa} \mid 1)
$$

and

$$
u\left[\hat{s}, 0, w^{s e p}(\hat{\theta} ; \hat{\theta}) ; \hat{\theta}\right]=v(1-\hat{s} \mid 0)-c(\hat{s}, \hat{\theta})+\frac{\delta}{1-\delta}\left[w^{s e p}(\hat{\theta} ; \hat{\theta})+v(1 \mid 0)\right] .
$$

If $u[0,1,0 ; \hat{\theta}]<u\left[\hat{s}, 0, w^{s e p}(\hat{\theta} ; \hat{\theta}) ; \hat{\theta}\right]$ then $\hat{\theta}$ strictly prefers to separate and, by Lemma 3 and monotonicity of payoffs in type, $u[0,1,0 ; \theta]<u\left[\sigma_{0}^{c}(\theta), 0, w^{s e p}(\theta ; \theta) ; \theta\right]$ for all $\theta>\hat{\theta}$. By Proposition 3, therefore, no D1 equilibrium with accepted types pooling on $s=0$ exists in this case. Suppose $u[0,1,0 ; \hat{\theta}] \geq u\left[\hat{s}, 0, w^{\text {sep }}(\hat{\theta} ; \hat{\theta}) ; \hat{\theta}\right]$. If the weak inequality in fact holds with equality then, by monotonicity of payoffs in type, Propositions 1 and 4 imply $\left(\sigma(\cdot \mid \hat{\theta}), \alpha_{0}\right)$ supports a D1 peer pressure equilibrium. Suppose the inequality holds strictly so, conditional on other agents' strategies, $\hat{\theta}$ strictly prefers pooling on $s=0$ and being accepted by the group to separating on $\hat{s}$ and being rejected by the group.

By Lemma 1(2), for any $\theta^{\prime}>\hat{\theta}$, the expected discounted payoff at $t=0$ from pooling on $s=0$, earning zero wage, and being accepted by the group is

$$
\begin{aligned}
u\left[0,1,0 ; \theta^{\prime}\right] & =v(1 \mid 1)+\frac{\delta}{1-\pi \delta}\left[v(1 \mid 1)+(1-\pi) \frac{\delta}{1-\delta} v(1 \mid 0)\right] \\
& >v(1 \mid 1)+\frac{\delta}{1-\delta} E_{(\pi)} v\left(1-\theta^{\prime} \tilde{\kappa} \mid 1\right)
\end{aligned}
$$

with the inequality following from the definition of $\hat{\theta}$. Therefore, by continuity of $E_{(\pi)} v(1-\theta \tilde{\kappa} \mid 1)$ and $w^{s e p}(\theta ; \hat{\theta})$ in $\theta$, if $u[0,1,0 ; \hat{\theta}]>u\left[\hat{s}, 0, w^{s e p}(\hat{\theta} ; \hat{\theta}) ; \hat{\theta}\right]$ then there exists an open interval of types $I=(\hat{\theta}, \hat{\theta}+\epsilon) \subseteq$ $R\left(\sigma(\cdot \mid \hat{\theta}), \alpha_{0}\right)$ such that, for all $\theta \in I, u[0,1,0 ; \theta]>u\left[\sigma_{0}(\theta \mid \hat{\theta}), 0, w^{s e p}(\theta ; \hat{\theta}) ; \theta\right]$. Holding $s=0$ fixed for the pooling set of types, consider an educational investment strategy, $\sigma\left(\cdot \mid \theta^{\prime}\right)$ where $\hat{\theta}<\theta^{\prime}<\hat{\theta}+\epsilon$. Since investing in no education implies a zero wage, conditional on $\alpha_{0}(0)=1$ all types $\theta \in[0, \hat{\theta}]$ are indifferent between playing $\sigma\left(\theta \mid \theta^{\prime}\right)$ or $\sigma(\theta \mid \hat{\theta})$. And by definition of $\sigma\left(\cdot \mid \theta^{\prime}\right)$ and $\theta^{\prime}>\hat{\theta}, \lim _{\eta \downarrow 0} \sigma_{a}\left(\theta^{\prime}+\eta \mid \theta^{\prime}\right)=\sigma_{0}^{c}\left(\theta^{\prime}\right)$; therefore, by Lemma $4, \theta^{\prime}$ strictly prefers playing $\sigma_{0}^{c}\left(\theta^{\prime} \mid \theta^{\prime}\right)$ to $\sigma\left(\theta^{\prime} \mid \hat{\theta}\right)=\sigma_{0}\left(\theta^{\prime} \mid \hat{\theta}\right)$. By definition of $\hat{\theta}, F(\hat{\theta} \mid \sigma(\theta \mid \hat{\theta})=0)=1$; 
so by $F$ smooth and Lemma 2, for $\theta^{\prime}=\hat{\theta}+\eta$ with $\eta>0$ sufficiently small, $\sigma\left(\theta \mid \theta^{\prime}\right)=0$ implies $\alpha_{0}(0)=$ 1. Consider an increasing sequence of educational investment strategies $\left\{\sigma\left(\cdot \mid \theta_{n}\right)\right\}_{\theta_{0}=\hat{\theta}}^{\theta_{\infty}=\bar{\theta}}$. By the preceding remarks, wages are constant at zero on the pooling segment and $w^{\operatorname{sep}}\left(\theta_{n} ; \theta_{n}\right)$ is strictly increasing in $\theta_{n}$ along the sequence and, for all $n, \alpha_{0}\left(\sigma\left(\theta \mid \theta_{n}\right)\right)=1$ only if $\sigma\left(\theta \mid \theta_{n}\right)=0$. Define the difference

$$
\Delta\left(\theta_{n}\right) \equiv u\left[0,1,0 ; \theta_{n}\right]-u\left[\sigma_{0}^{c}\left(\theta_{n}\right), 0, w^{s e p}\left(\theta_{n} ; \theta_{n}\right) ; \theta_{n}\right]
$$

Doing the calculus and taking account of the definition of $\sigma_{0}^{c}\left(\theta_{n}\right)$ as the complete information optimal decision for $\theta_{n}$ conditional on being excluded from the group, it is straightforward to confirm that $\Delta\left(\theta_{n}\right)$ is strictly decreasing in $\theta_{n}$. There are two possibilities: either $\Delta\left(\theta_{n}\right)=0$ for some $\theta_{n} \in\left(\hat{\theta}, \theta^{\#}\right]$, where $\theta^{\#}$ is defined by $F\left(\hat{\theta} \mid \sigma\left(\theta \mid \theta^{\#}\right)=0\right)=F_{0}<1$; or $\Delta\left(\theta_{n}\right)>0$ at $\theta_{n}=\theta^{\#}$. In the first case Proposition 4 implies the strategies $\left(\sigma\left(\cdot \mid \theta_{n}\right), \alpha_{0}\right)$ support a D1 peer pressure equilibrium. Consider the second case. By Lemma 2 and definition of $\theta^{\#}$, the group is indifferent between accepting and rejecting any individual choosing $\sigma\left(\theta \mid \theta^{\#}\right)=0$; and by definition of $\sigma_{0}^{c}(\cdot)$,

$$
u\left[0,0,0 ; \theta^{\#}\right]<u\left[\sigma_{0}^{c}\left(\theta^{\#} \mid \theta^{\#}\right), 0, w^{s e p}\left(\theta^{\#} ; \theta^{\#}\right) ; \theta^{\#}\right] .
$$

Hence there exists some probability $\alpha_{0}(0)=\alpha^{\#} \in(0,1)$ such that $\alpha^{\#}$ is a best response to $s=0$ and

$$
\alpha^{\#} u\left[0,1,0 ; \theta^{\#}\right]+\left(1-\alpha^{\#}\right) u\left[0,0,0 ; \theta^{\#}\right]=u\left[\sigma_{0}^{c}\left(\theta^{\#} \mid \theta^{\#}\right), 0, w^{s e p}\left(\theta^{\#} ; \theta^{\#}\right) ; \theta^{\#}\right] .
$$

By payoff monotonicity, given the mixed response to $s=0$ all types $\theta>\theta^{\#}$ strictly prefer to separate on $\sigma_{0}\left(\theta \mid \theta^{\#}\right)>\sigma_{0}^{c}\left(\theta^{\#} \mid \theta^{\#}\right)$ than to pool on $s=0$. And since educational investment cannot be negative, no type $\theta<\theta^{\#}$ can deviate to a lower investment. By D1, any deviation to some out-of-equilibrium level $s^{\prime} \in\left(0, \sigma_{0}^{c}\left(\theta^{\#} \mid \theta^{\#}\right)\right)$ is believed by the group to be sent by $\theta^{\#}>\hat{\theta}$ and so induces sure rejection by the group. Therefore no type can make a profitable deviation and the strategies again support a D1 equilibrium. This completes the first step of the argument; it remains to show there exists some $\delta_{1} \in(0,1)$ such that $\hat{\theta}(\delta)$ weakly prefers pooling on $s=0$ to separating with $\sigma_{0}^{c}(\hat{\theta}(\delta) \mid \hat{\theta}(\delta))$ if and only if $\delta \leq \delta_{1}$.

Assume the strategy $\sigma(\cdot \mid \hat{\theta}(\delta))$ is to be played with pooling on $s=0$. Then

$$
u[0,1,0 ; \hat{\theta}(\delta)]=v(1 \mid 1)+\frac{\delta}{1-\delta} E_{(\pi)} v(1-\hat{\theta}(\delta) \tilde{\kappa} \mid 1)
$$

and

$$
\frac{d u[0,1,0 ; \hat{\theta}(\delta)]}{d \delta}=\frac{E_{(\pi)} v(1-\hat{\theta}(\delta) \tilde{\kappa} \mid 1)}{[1-\delta]^{2}}-\frac{\delta}{1-\delta} \frac{\partial v(1-\hat{\theta}(\delta) k \mid 1)}{\partial l}(1-\pi) k \hat{\theta}^{\prime}(\delta) .
$$

Similarly let $s(\hat{\theta}(\delta), \delta) \equiv \sigma_{0}^{c}(\hat{\theta}(\delta))$ and $[\hat{v}-\hat{c}](\delta) \equiv[v(1-s(\hat{\theta}(\delta), \delta) \mid 0)-c(s(\hat{\theta}(\delta), \delta), \hat{\theta}(\delta))]$, so

$$
\begin{aligned}
u\left[\sigma_{0}^{c}(\hat{\theta}(\delta)), 0, w^{s e p}(\hat{\theta}(\delta) ; \hat{\theta}(\delta)) ; \hat{\theta}(\delta)\right]= & \\
& {[\hat{v}-\hat{c}](\delta)+\frac{\delta}{1-\delta}[y(s(\hat{\theta}(\delta), \delta), \hat{\theta}(\delta))+v(1 \mid 0)] }
\end{aligned}
$$


and, by the Envelope Theorem,

$$
\begin{aligned}
& \frac{d u\left[\sigma_{0}^{c}(\hat{\theta}(\delta)), 0, w^{s e p}(\hat{\theta}(\delta) ; \hat{\theta}(\delta)) ; \hat{\theta}(\delta)\right]}{d \delta} \\
= & {\left[\frac{\delta}{1-\delta} \frac{\partial y(\cdot, \hat{\theta}(\delta))}{\partial \theta}-\frac{\partial c(\cdot, \hat{\theta}(\delta))}{\partial \theta}\right] \hat{\theta}^{\prime}(\delta)+\frac{y(\cdot, \hat{\theta}(\delta))+v(1 \mid 0)}{[1-\delta]^{2}} . }
\end{aligned}
$$

By $(15), \lim _{\delta \downarrow 0} \hat{\theta}(\delta)=0$. Hence

$$
\begin{aligned}
\lim _{\delta \downarrow 0} \Delta(\hat{\theta}(\delta)) & =u[0,1,0 ; 0]-u\left[\sigma_{0}^{c}(0), 0, w^{s e p}(0 ; 0) ; 0\right] \\
& =v(1 \mid 1)-v(1 \mid 0)>0 .
\end{aligned}
$$

And since $\Delta(\hat{\theta}(\delta))\left\{\begin{array}{l}\geq \\ <\end{array}\right\} 0$ as

$$
\begin{aligned}
& {\left[(1-\delta) v(1 \mid 1)+\delta E_{(\pi)} v(1-\hat{\theta}(\delta) \tilde{\kappa} \mid 1)\right]\left\{\begin{array}{l}
\geq \\
<
\end{array}\right\},} \\
& {[(1-\delta)[\hat{v}-\hat{c}]+\delta[y(s(\hat{\theta}(\delta), \delta), \hat{\theta}(\delta))+v(1 \mid 0)]],}
\end{aligned}
$$

(15) and $\hat{\theta}(\delta)<1 / k$ imply $\lim _{\delta \uparrow 1} \Delta(\hat{\theta}(\delta))<0$. Therefore, by continuity there exists at least one $\delta<1$ at which $\Delta(\hat{\theta}(\delta))=0$. Let $\delta_{1}$ denote any value in $(0,1)$ at which $\Delta(\hat{\theta}(\delta))=0$. Consider the difference

$$
\Delta_{\delta_{1}}=\frac{d u\left[\sigma_{0}^{c}\left(\hat{\theta}\left(\delta_{1}\right)\right), 0, w^{s e p}\left(\hat{\theta}\left(\delta_{1}\right) ; \hat{\theta}\left(\delta_{1}\right)\right) ; \hat{\theta}\left(\delta_{1}\right)\right]}{d \delta}-\frac{d u\left[0,1,0 ; \hat{\theta}\left(\delta_{1}\right)\right]}{d \delta} .
$$

Using (25) and (26), $\Delta_{\delta_{1}}>0$ if and only if

$$
\begin{aligned}
& {\left[\frac{\delta_{1}}{1-\delta_{1}}\left(\frac{\partial y\left(\cdot, \hat{\theta}\left(\delta_{1}\right)\right)}{\partial \theta}+\frac{\partial v\left(1-\hat{\theta}\left(\delta_{1}\right) k \mid 1\right)}{\partial l}(1-\pi) k\right)-\frac{\partial c\left(\cdot, \hat{\theta}\left(\delta_{1}\right)\right)}{\partial \theta}\right] \hat{\theta}^{\prime}\left(\delta_{1}\right) } \\
> & \frac{1}{\left[1-\delta_{1}\right]^{2}}\left[E_{(\pi)} v\left(1-\hat{\theta}\left(\delta_{1}\right) \tilde{\kappa} \mid 1\right)-\left(y\left(\cdot, \hat{\theta}\left(\delta_{1}\right)\right)+v(1 \mid 0)\right)\right] .
\end{aligned}
$$

By definition, $\Delta\left(\hat{\theta}\left(\delta_{1}\right)\right)=0$ so the RHS of the preceding inequality is strictly negative, and the maintained assumptions imply the LHS of the inequality is strictly positive. Therefore, (27) and continuity imply there can exist at most one value of $\delta \in(0,1)$ at which $\Delta(\hat{\theta}(\delta))=0$. Setting this value equal to $\delta_{1}$ then proves the sufficiency part of the Proposition.

(Necessity) To establish the necessity claim, assume $\delta>\delta_{1}$. By the argument for Sufficiency, there is no D1 equilibrium in which $\sigma\left(\theta \mid \theta^{\prime}\right)=0$ for all $\theta \leq \theta^{\prime} \in[\hat{\theta}(\delta), \bar{\theta})$. Therefore, if there is a D1 peer pressure equilibrium at $\delta$, there must exist some educational investment effort $s_{0}$ such that: (i) for all $\theta \leq \hat{\theta}(\delta)$, $\sigma(\theta \mid \hat{\theta}(\delta))=s_{0}>0$; (ii) $\hat{\theta}(\delta)$ weakly prefers choosing $s_{0}$ to the separating investment level $\sigma_{0}^{c}(\hat{\theta}(\delta)$ ); and (iii) the lowest type, $\theta=0$, weakly prefers choosing $s_{0}$ to choosing any smaller educational effort. Noting that assumptions on $F$ insure $\omega\left(s_{0} ; \theta^{\prime}\right)$ is increasing in $\theta^{\prime}$, Properties (i) and (ii) follow from the same reasoning as for the first part of the Sufficiency argument, with pooling on $s_{0}$ rather than on zero; to see why (iii) 
must hold, suppose all types $\theta \in(0, \hat{\theta}(\delta)]$ pool on $\sigma(\theta \mid \hat{\theta}(\delta))=s_{0}$ and $\theta=0$ deviates to any educational investment level $s<s_{0}$. Such a deviation constitutes an out-of-equilibrium message and, by monotonicity, D1 requires the firms' and the group's beliefs about the type sending the message to be concentrated on the lowest type. Hence, (6) and (8) imply the wage induced by such a deviation is $y(s, 0)<\omega\left(s_{0} ; \hat{\theta}(\delta)\right)$, and Lemma 2 implies the group surely accepts $\theta=0$ consequent on observing the deviation. So if $\theta=0$ strictly prefers to separate at some $s<s_{0}$, then pooling on $s_{0}$ for the accepted set of types is untenable in any D1 peer pressure equilibrium. Therefore, D1 equilibria exist at $\delta$ only if there is some $s_{0}$ such that $(i)$ holds and, for all $s \in\left[0, s_{0}\right)$,

$$
\begin{aligned}
& v\left(1-s_{0} \mid 1\right)-c\left(s_{0}, 0\right)+\frac{\delta}{1-\delta}\left[\omega\left(s_{0} ; \hat{\theta}(\delta)\right)+v(1 \mid 1)\right] \\
\geq & v(1-s \mid 1)-c(s, 0)+\frac{\delta}{1-\delta}[y(s ; 0)+v(1 \mid 1)]
\end{aligned}
$$

and

$$
\begin{aligned}
& v\left(1-s_{0} \mid 1\right)-c\left(s_{0}, \hat{\theta}(\delta)\right)+\frac{\delta}{1-\delta}\left[\omega\left(s_{0} ; \hat{\theta}(\delta)\right)+E_{(\pi)} v(1-\hat{\theta}(\delta) \tilde{\kappa} \mid 1)\right] \\
\geq & v\left(1-\sigma_{0}^{c}(\hat{\theta}(\delta)) \mid 0\right)-c\left(\sigma_{0}^{c}(\hat{\theta}(\delta)), \hat{\theta}(\delta)\right)+\frac{\delta}{1-\delta}\left[w^{s e p}(\hat{\theta}(\delta) ; \hat{\theta}(\delta))+v(1 \mid 0)\right] .
\end{aligned}
$$

Collecting terms, these two inequalities can be written equivalently for any $\delta \in\left[\delta_{1}, 1\right)$ as

$$
\omega\left(s_{0} ; \hat{\theta}(\delta)\right) \geq \frac{1-\delta}{\delta}\left[v(1-s \mid 1)-c(s, 0)-v\left(1-s_{0} \mid 1\right)+c\left(s_{0}, 0\right)\right]+y(s ; 0) ;
$$

and

$$
\begin{aligned}
\omega\left(s_{0} ; \hat{\theta}(\delta)\right)-w^{s e p}(\hat{\theta}(\delta) ; \hat{\theta}(\delta)) & \geq v(1 \mid 0)-E_{(\pi)} v(1-\hat{\theta}(\delta) \tilde{\kappa} \mid 1)+ \\
& \frac{1-\delta}{\delta}\left[v\left(1-\sigma_{0}^{c}(\hat{\theta}(\delta)) \mid 0\right)-c\left(\sigma_{0}^{c}(\hat{\theta}(\delta)), \hat{\theta}(\delta)\right)-v\left(1-s_{0} \mid 1\right)+c\left(s_{0}, \hat{\theta}(\delta)\right)\right] .
\end{aligned}
$$

Suppose there exists an investment level $s_{0}>0$ at $\delta=\delta_{1}$ such that both (28) and (29) obtain, and let $\delta \rightarrow 1$ holding $s_{0}$ fixed. From Lemma $1, \hat{\theta}(\delta)$ is strictly increasing in $\delta$ on $(0,1)$ with $\lim _{\delta \uparrow 1} \hat{\theta}(\delta)<\infty$. Hence, $\omega\left(s_{0} ; \hat{\theta}(\delta)\right)$ is nondecreasing in $\delta, \lim _{\delta \uparrow 1} \omega\left(s_{0} ; \hat{\theta}(\delta)\right) \geq \omega\left(s_{0} ; \hat{\theta}\left(\delta_{1}\right)\right)$, and (28) continues to hold as we proceed to the limit. Consider $(29)$. By Lemma $1, \hat{\theta}(\delta)<1 / k$ for all $\delta<1$. Therefore, since every term in the square brackets on $R H S(29)$ is finite under the maintained assumptions, $\lim _{\delta \uparrow 1} R H S(29) \geq 0$. But $\sigma_{0}^{c}(\hat{\theta}(\delta))>s_{0}$ for all $\delta \in\left[\delta_{1}, 1\right)$, so $\omega\left(s_{0} ; \hat{\theta}(\delta)\right)<w^{\operatorname{sep}}(\hat{\theta}(\delta) ; \hat{\theta}(\delta))$ all $\delta \in\left[\delta_{1}, 1\right)$ which implies

$$
\lim _{\delta \rightarrow 1}\left[\omega\left(s_{0} ; \hat{\theta}(\delta)\right)-w^{\operatorname{sep}}(\hat{\theta}(\delta) ; \hat{\theta}(\delta))\right]<0 .
$$

Hence, (29) cannot hold for $\delta$ sufficiently high. Therefore, if both (28) and (29) hold at $\delta=\delta_{1}$ for $s_{0}>0$, there must exist some $\delta_{2} \in\left(\delta_{1}, 1\right)$ such that (29) fails at every $\delta>\delta_{2}$. This completes the proof.

Proof of Proposition 6 This proposition is proved by the argument for the Sufficiency claim of Proposition 5. 
Proof of Proposition 7 Given the separating assumption on the restriction of $\sigma^{*}$ to $R\left(\sigma^{*}, \alpha_{0}^{*}\right)$, Proposition $3(3)$ says $\inf R\left(\sigma^{*}, \alpha_{0}^{*}\right) \equiv \theta^{*} \geq \hat{\theta}(\delta)$ and Proposition 3(2) implies there must be a pooling segment $\left(\theta_{1}, \theta^{*}\right)$ on which $\sigma^{*}$ is constant. If $\theta_{1} \geq \hat{\theta}(\delta)$ then Lemma 2 and sequential rationality imply $\alpha_{0}^{*}\left(\sigma^{*}(\theta)\right)=0$, contradicting $\theta^{*}=\inf R\left(\sigma^{*}, \alpha_{0}^{*}\right)$; so $\theta_{1}<\hat{\theta}\left(\delta ; \mathbf{1}_{0}\right)$. And if $\theta_{1}=0$ then the equilibrium would satisfy the D1 refinement, contradicting $\delta>\delta_{1}$ by Proposition 4. Because Lemma 3 and $\theta_{1}>0$ give $\sigma^{*}(\theta) \in\left(0, \sigma_{0}^{c}\left(\theta^{*}\right)\right)$ for all $\theta \in\left(\theta_{1}, \theta^{*}\right)$, these facts establish claim (1). Claim (2) simply exhausts the possibilities for any equilibrium behaviors on the segment $\left[0, \theta_{1}\right)$.

Proof of Corollary 1 The claim follows directly from Proposition 3(2), Proposition 3(3) and the definition of $\hat{\theta}(\delta)$ as the type just indifferent between remaining in the group and contributing for all $\kappa_{t}$, and contributing to the group only if $\kappa_{t}=0$.

Proof of Proposition 8 The strategy [T1] is easily seen to be a best response to [T2] for the post-school years. So fix [T1] and consider an individual group member $\theta$ asked to contribute $k>0$ in period $t \geq 1$ (trivially, if $\kappa_{t}=0, \theta$ 's best response is $\tau(0, \theta)=d_{t}=1$ ). The discounted expected values to $\theta$ from contributing $k$ and from stating she will contribute, being accepted, and reneging on her statement, are given by expressions (12) and (13), respectively, above. That is, $\theta$ is indifferent between always contributing $k$, and only claiming an intention to contribute, but in fact reneging on her claim once accepted by the group in the period, iff $\theta=\hat{\theta}(\delta)$ as defined earlier. On the other hand, $\theta$ 's expected discounted payoff under [T1] from stating she will not contribute $k$ in period $t$ (but only contribute when $\kappa_{t}=0$ ), is

$$
w+v(j \mid 0)+\frac{\delta}{1-\delta}[w+\pi v(j \mid 1)+(1-\pi) v(j \mid 0)]
$$

Hence, under $[T 1]$, the difference between the payoff from stating an intention to contribute and reneging, and that from stating an intention not to contribute, is independent of type and given by

$$
\left[v(j \mid 1)+\frac{\delta}{1-\delta} v(j \mid 0)\right]-\left[v(j \mid 0)+\frac{\delta}{1-\delta}[\pi v(j \mid 1)+(1-\pi) v(j \mid 0)]\right] .
$$

Collecting terms this difference is nonpositive if and only if $\delta \geq 1 /[1+\pi]$. Therefore, given this inequality, all types prefer to be honest about their intentions to contribute and so be accepted by the group whenever they propose to contribute, to dissembling when the required contribution is high and reaping the one period gain from the deception. Now by definition, $\theta^{T}$ is the type indifferent between always contributing and only contributing at low cost, $\kappa_{t}=0$. From (12), at any wage the expected payoff from always contributing is strictly decreasing in $\theta$. It follows that $\delta \geq 1 /[1+\pi]$ implies $\theta^{T} \leq \hat{\theta}(\delta)$ and $[T 2]$ describes the best response to $[T 1]$.

If $\delta<1 /[1+\pi]$ then $\theta^{T}>\hat{\theta}(\delta)$ and all types $\theta>\hat{\theta}(\delta)$ strictly prefer to lie about their intent to contribute $k$ in any period, in which case $[T 1]$ and $[T 2]$ cannot constitute equilibrium strategies.

Since only types $\theta \leq \theta^{T}$ always contribute under [T1] and [T2], the tolerant group's expected payoff from accepting an individual in the school years with education $\sigma(\theta)$ is

$$
F\left(\theta^{T} \mid \sigma(\theta)\right) \frac{b}{1-\gamma}+\left[1-F\left(\theta^{T} \mid \sigma(\theta)\right)\right] \frac{\pi b}{1-\pi \gamma} .
$$


Thus accepting all individuals is rational if and only $F\left(\theta^{T} \mid \sigma(\theta)\right) \geq 0$, which is trivially the case.

Assume there exists a tolerant equilibrium. Then because all types are accepted by the group in the school years irrespective of their educational investment, and all types strictly prefer to be honest regarding group contributions in the post-school years, there is no incentive induced by [T1] for an individual to conceal his or her true type from the group. Consequently, given all types are accepted, the separating result follows from the standard existence argument for the Spence job-market signaling game. And since the tolerant group's expected payoff conditional on accepting $\theta$ is no smaller than $\pi b /(1-\pi \gamma)$, accepting all types in the school years is a best response here.

Proof of Proposition 9 From the argument for Lemma 2, above, conditional on accepting $\theta$, the average payoff to the group in the peer pressure equilibrium is (discounted one period)

$$
F(\hat{\theta}(\delta) \mid \sigma(\theta)) \frac{b}{1-\gamma}+[1-F(\hat{\theta}(\delta) \mid \sigma(\theta))] \frac{[\pi b-(1-\pi) B k]}{1-\pi \gamma} .
$$

And since only types $\theta \leq \theta^{T}$ always contribute under [T1] and [T2], the tolerant group's average expected (ex ante) payoff conditional on accepting $\theta$ is

$$
F\left(\theta^{T}\right) \frac{b}{1-\gamma}+\left[1-F\left(\theta^{T}\right)\right] \frac{\pi b}{1-\pi \gamma} .
$$

Taking the difference between these two values gives the result.

\section{References}

[1] Ainworth-Darnell,J.W., and Downey, D. 1998. "Assessing the Oppositional Culture Explanation for Racial/Ethnic Differences in School Performance." American Sociological Review 63: 536-553.

[2] Akerlof, G. 1976. The economics of caste and of the rat race and other woeful tales, Quarterly J. Economics, November: 599-61\%.

[3] Akerlof, G. 1980. A theory of social custom of which unemployment may be one consequence, Quarterly J. Economics, June: 599-61\%.

[4] Akerlof, G. 1997. Social distance and social decisions. Econometrica, 65: 1005-2\%.

[5] Akerlof, G. and R. Kranton. 1999. Economics and identity. forthcoming, Quarterly J. Economics.

[6] Anderson, E. 1999. Code of the Streets: Decency, Violence, and the Moral Life of the Inner City. Norton, W. W. \& Company, Inc.

[7] Asch, S.E. 1952. "Effects of Group Pressure upon Modification and Distortion of Judgements," in Swanson, G.E., Newcomb, T.M. and Hartley E.L. eds. Readings in Social Psychology. NY: Holt, Rhinehart, and Winston. 
[8] Austen-Smith, D. 2002. "Peer Pressure and Job Market Signalling." Center for Mathematical Studies in Economics and Management Science, Discussion Paper \#1352. Northwestern University.

[9] Banks, J. 1990. Signaling Models in Political Science, NY: Harwood.

[10] Banks, J. and J. Sobel. 1987. Equilibrium selection in signaling games. Econometrica, 55: 647-61.

[11] Bernheim, B.D. 1994. A theory of conformity. J. Political Economy, 102: 841-77.

[12] Brooks-Gunn, Jeanne and Greg J. Duncan, eds. The Consequences of Growing Up Poor. (New York: Russell Sage, 2001).

[13] Cook, P.J., Ludwig, L. 1998. "The Burden of 'Acting White': Do Black Adolescents Disparage Academic Achievement?" In Christopher Jenks and Meredith Phillips, eds., The Black-White Test Score Gap. Brookings Press

[14] Cho, I-K. and D. Kreps. 1987. Signaling games and stable equilibria. Quarterly J. Economics, May: 179-221.

[15] Cho, I-K. and J. Sobel. 1990. Strategic stability and uniqueness in signaling games. J. Economic Theory, 50: 381-413.

[16] Cole, H., G. Mailath and A. Postlewaite. 1992. Social norms, savings behavior and growth. J. Political Economy, 100: 1092-1125.

[17] Ferguson, R. 2001. "A Diagnostic Analysis of Black-White GPA Disparities in Shaker Heights, Ohio." Brooking Papers on Education Policy, (forthcoming)

[18] Fordham, S. and J. Ogbu. 1986. Black students' school success: coping with the "Burden of Acting White". The Urban Review, 18: 176-206.

[19] Frazier, F. 1957. Black Bourgeoisie. Glencoe IL: Free Press.

[20] Fryer, R., 2003. "An Economic Approach to Cultural Capital." manuscript. University of Chicago.

[21] Fryer, R., and Levitt, S. 2002. "Understanding the Black-White Test Score Gap in the First Two Years of School." National Bureau of Economic Research, Working Paper 8975.

[22] Herrnstein, R, and Charles, M. 1994. The Bell Curve: Intelligence and Class Structure in American Life. The Free Press.

[23] Jargowsky, Paul, and Bane, Mary Jo., 1991 "Ghetto Poverty in the United States, 1970-1980." in The Urban Underclass, Christopher Jencks, and Paul Peterson eds. The Brookings Institution. Washington D.C. 
[24] Jencks, C., and Phillips, M. 1998. The Black-White Test Score Gap. Brooking Press.

[25] Jensen, A. 1998. The G Factor: The Science of Mental Ability. Greenwood Publishing Group

[26] Kandori, M. 1992. Social norms and community enforcement. Review of Economic Studies, 59: 63-80.

[27] Lindbeck, A. and J. Weibull. 1999. Social norms and economic incentives in the welfare state. Quarterly J. Economics, February: 1-35.

[28] Loury, G. 2002. The Anatomy of Racial Inequality (Harvard University Press: Cambridge Massachusetts)

[29] Massey, D., and Denton, N. 1993. American Apartheid: Segregation and the Making of the Underclass. Cambridge, MA: Harvard University Press.

[30] Milgrom, P. and S. Oster. 1987. Job discrimination, market forces and the invisibility hypothesis. Quarterly J. Economics, August: 453-76.

[31] Olson, S. 2002. Mapping Human History. Houghton Mifflin Company.

[32] Pattillo-McCoy, M. 1999. Black Picket Fences: Privilege and Peril Among the Black Middle Class. The University of Chicago Press.

[33] Pertroni, F.A., and Hirsch, E.A. 1970. Two, Four, Six, Eight, When You Gonna Integrate? (New York: Behavioral Publications).

[34] Phelps, E.S., "The Statistical Theory of Racism and Sexism," American Economic Review, (September 1972) 659-61.

[35] Riley, J G. 1979. "Informational Equilibrium," Econometrica, 47, 331-360.

[36] Rushton, P.J. 2000. Race, Evolution, and Behavior: A Life History Perspective. NJ: Transaction Publishers

[37] Spence, M. 1974. Market Signaling. Cambridge: Harvard University Press.

[38] Suskind, R. 1998. A Hope Unseen. NY: Broadway. 